\title{
LA EPIGRAFÍA ROMANA DEL PAÍS VASCO: UNA REVISIÓN HISTORIOGRÁFICA*
}

\author{
ROMAN EPIGRAPHY OF THE BASQUE COUNTRY: A HISTORIOGRAPHIC REVIEW
}

PILAR CIPRÉS TORRES

Universidad del País Vasco/ Euskal Herriko Unibertsitatea

pilar.cipres@ehu.eus http://orcid.org/0000-0001-5439-658X

Recepción: 16-03-2018

Aceptación: 28-05-2018

\section{Resumen}

El estudio de la epigrafía romana del País Vasco ha estado asociado, desde el siglo XVII hasta hoy, al interés por la Antigüedad Clásica en el País Vasco. Este trabajo tiene como objetivo una revisión historiográfica, en la que se analiza la influencia, por un lado, de una historia al servicio de determinados intereses políticos y, por otro, de una historia crítica basada en los restos epigráficos y arqueológicos aparecidos en el territorio del País Vasco.

Palabras clave. País Vasco; epigrafía latina; historiografía; dominación romana.

\begin{abstract}
The study of the Roman epigraphy of the Basque Country has been associated, from the 17th century until today, with the interest in Classical Antiquity in the Basque Country. This paper aims to provide a historiographic review that analyzes the influence of a history at the service of certain political interests, and of a critical history based on the epigraphic and archaeological remains that have appeared in its territory.
\end{abstract}

Key words. Basque Country; Roman epigraphy; historiography; Roman conquest.

\footnotetext{
* Este trabajo ha sido realizado dentro del Proyecto de Investigación HAR2015-65526-P (MINECO/FEDER UE) y del Grupo de Investigación GIU 16/64 (UPV/EHU).
} 
Durante la celebración del centenario de L'Année Epigraphique los profesores Etienne y Le Roux (1990: 101) al hacer un balance de las investigaciones francesas sobre la epigrafía romana de la Península Ibérica durante el último siglo escribían que el epigrafista se inscribe «librement et de manière autonome, dans une histoire épigraphique et scientifique séculaire marquée par des traditions culturelles, par des idéologies et par des préjugés». La consideración de estos aspectos, sin duda alguna, permite comprender mejor la historia de la epigrafía romana del y en el País Vasco desde el siglo XVII -momento en el que se publican las primeras inscripciones conocidas- hasta nuestros días. La lectura atenta de los diferentes trabajos que han ido apareciendo a lo largo de estos siglos muestra las pautas que han marcado su evolución. Factores históricos, sociales, ideológicos y científicos han configurado su desarrollo, condicionando no solo el descubrimiento de inscripciones -sujeto en muchas ocasiones al azar-y su estudio, sino también su valoración. El estudio de la epigrafía romana ha estado asociado con el interés suscitado por la Antigüedad en el País Vasco y el significado histórico concedido a los materiales romanos documentados en su territorio. En este sentido, hay que considerar, por un lado, la influencia ejercida por una concepción de la historia del País Vasco asociada a determinadas reivindicaciones políticas y, por otro, por la configuración de la historia, la arqueología y la epigrafía como disciplinas cada vez más «científicas», cuya aceptación por parte de un sector de los intelectuales vascos con formación e inquietudes culturales, favoreció el desarrollo de un conocimiento de la Antigüedad basado en las fuentes. A lo largo de las siguientes páginas vamos a tratar de hacer un repaso del proceso seguido por los estudios epigráficos en el País Vasco, donde estos elementos interrelacionados entre sí tendrán un grado de influencia distinto.

\section{UNA CONCEPCIÓN IDEOLÓGICA DE LA HISTORIA DEL PAIIS VASCO: LA VALORACIÓN DE LOS RESTOS EPIGRÁFICOS ROMANOS}

L. del Prestamero en 1792 al inicio de su manuscrito Camino militar romano que pasaba por Álava ${ }^{1}$, criticaba el poco interés que mostraban los escritores por los vestigios romanos en Álava, persuadidos de que los romanos no llegaron a asentarse en su territorio y que, por lo tanto, no habían dejado rastros de su presencia, una afirmación que contrastaba con el hallazgo en la provincia de «diferentes inscripciones y otras antigüedades» (González de Echávarri, 1900: 276-277). Un siglo más tarde, F. Baraibar ${ }^{2}$ en

1. Publicado en González de Echávarri, 1900: 275-316.

2. Sobre el papel de F. Baraibar en el conocimiento de la epigrafía romana en Álava, vid. infra. el Discurso leído en el Ateneo de Vitoria con motivo de la inauguración del curso 1882-1883 realiza una crítica similar, que hace extensible a escritores contemporáneos como Landázuri, Ortiz de Zárate y Mateo de Moraza, quienes, oponiéndose a la evidencia ofrecida por los numerosos monumentos arqueológicos y epigráficos aparecidos en el País Vasco, seguían negando la dominación romana con el argumento de que estos testimonios -en particular inscripciones y monedas - «habrían sido traídos por capricho de algún coleccionador» (Baraibar, 1883: 7). Ambos autores hacen referencia a una actitud bastante extendida entre aquellos intelectuales que estaban interesados en la elaboración de una historia del País Vasco construida a partir de dogmas y mitos apologéticos destinados a defender las tradiciones y los privilegios derivados de los Fueros ${ }^{3}$. Aunque los orígenes de esta historia se remontan al siglo XIV, su configuración definitiva se produce en el siglo XVI perdurando entre algunos sectores sociales hasta el siglo XX. Durante este tiempo su arraigo dificulta el desarrollo de una historia crítica apoyada en las fuentes tanto literarias como arqueológicas, epigráficas y numismáticas. Así, por ejemplo, la penetración del pensamiento ilustrado en el País Vasco, que supone la llegada de una concepción de la historia elaborada con una metodología moderna y sometida a una crítica racional, no consigue desterrar esta visión tradicional. Son conocidas las contradicciones que se generan a finales del siglo XVIII en el seno de la Real Sociedad Bascongada de Amigos del País, la institución que mejor representa las ideas ilustradas en las tres provincias vascas. Fundada en $1765^{4}$ e inmersa en el contexto político de la época, sus miembros se debaten entre la realización de una historia crítica, en la que las fuentes adquieren gran importancia, y aquella legitimadora de determinadas posiciones políticas (Fernández Sebastián, 1991).

Como parte de esta «pseudohistoria» ${ }^{5}$ se construye una imagen ficticia de la Antigüedad, basada en una

3. Detrás de todo este planteamiento descansa la justificación de la situación política del momento frente al poder central, fundamentalmente, la justificación y defensa de los Fueros, la antigüedad y la soberanía de la nobleza vasca, etc. Vid. entre otros, Fernández Sebastián (1991) y Duplá y Cortadella (2014).

4. Sus miembros se dedicaron a actividades diversas que iban desde la agricultura hasta las Bellas Letras, existiendo una Comisión de Historia, Política y Buenas Letras. En el campo de la historia su objetivo fue impulsar la elaboración de una Historia Nacional de las provincias vascongadas, que finalmente no se realizó. Sobre la institución vid. Areta Armentia (1976), Urdiain (1985); Fernández Sebastián (1991), Ortiz de Urbina (1996; 1997), Larrañaga (1998-1999) y Duplá y Cortadella (2014).

5. Esta recreación del pasado, aunque con unas características propias, no es muy diferente de la que experimenta la historiografía en el resto de España con el desarrollo de un conocimiento pseudohistórico que lo que busca es legitimar hechos creando una documentación falsa, que incluye también 
interpretación interesada de los textos clásicos sobre la conquista del norte peninsular y en la creación de una serie de mitos $^{6}$, cuyo objetivo era demostrar la independencia primitiva del País Vasco - de la que se consideraba una prueba irrefutable la pervivencia del euskera- frente a la presencia de invasores extranjeros, especialmente, de los romanos, que habían llegado a dominar el mundo. En este marco se inscriben las tesis «vascocantabristas», que defienden la integración en una Cantabria Antigua de los territorios de Vizcaya, Guipúzcoa y Álava ${ }^{7}$, que nunca habrían llegado a ser sometidos. La aceptación de estos planteamientos significaba negar la sumisión total de la Península Ibérica al poder romano en clara oposición con lo que las fuentes clásicas documentan ${ }^{8}$. A pesar de su fuerte arraigo, estas teorías encontraron, desde una época temprana, detractores entre intelectuales del país, como d'Oihenart, o foráneos, como Zurita, Flórez o Risco ${ }^{9}$. En la polémica que genera el vascocantabrismo surgen contradicciones entre muchos intelectuales interesados en la recopilación de los vestigios romanos, como Moret y Prestamero -este último miembro de la Bascongada-, quienes, sin embargo, siguen hablando de una Cantabria Antigua amplia, que incluía los territorios vascos (Larrañaga, 1998-1999; Duplá y Cortadella, 2014).

La idea de la no-dominación romana, en un primer momento, encontró apoyo en el reducido número de restos materiales descubiertos en las tres provincias vascas. La escasez de vestigios arqueológicos

testimonios epigráficos (Gimeno, 2012). En el caso vasco no se trata de crear documentos falsos, sino de negar el valor como fuente histórica de los restos romanos documentados.

6. Los mitos fundamentales son: la consideración de los vascos descendientes de Tubal como los primeros pobladores de la Península y del euskera como la primera lengua peninsular; la existencia de un monoteismo primitivo entre los vascos y su temprana evangelización; el origen pactado del Señorío de Vizcaya, etc. (Duplá y Emborujo, 1991; Larrañaga, 1998-1999).

7. Básicamente son Vizcaya y Guipúzcoa las provincias incluidas dentro de la Cantabria antigua.

8. Curiosamente la base de toda esta argumentación descansa en una interpretación muy peculiar de la información que transmiten los autores greco-romanos.

9. Sobre A. d'Oihenart vid. Larrañaga, 1996 y 1998-1999. El historiador aragonés Jerónimo Zurita criticó la inclusión de Vasconia en Cantabria ya en el siglo XVI, si bien su obra no se publicó hasta 1683 (Fernández Sebastián, 1991). Entre los intelectuales que se opusieron a esta construcción se encuentra también G. Mayans, una de las figuras clave de la Ilustración española en el campo de la historia y de la epigrafía (Gimeno, 2012). Defensor de los fueros aragoneses, catalanes y valencianos y desde una posición crítica con la pseudohistoria rechaza esta visión por la utilización de argumentos cargados de fabulación e irracionalidad (Fernández Sebastián, 1991). De la historia del País Vasco ofrecida por el padre Flórez (1887) o por el Diccionario Geográfico Histórico (1802) se hace también una lectura política, en la que se pone de relieve - especialmente en el caso del Diccionario- su carácter antiforal (Mañaricúa, 1973; Larrañaga, 1998-1999). considerados relevantes, como teatros, circos, acueductos, etc., fue utilizada de forma reiterada a lo largo del siglo XVIII e, incluso, del XIX como el principal argumento para rechazar la integración en el Imperio romano. Como cabe esperar, esta visión condicionó el interés y la valoración de los restos romanos atestiguados, llegando algunos eruditos a atribuirles una procedencia foránea, con la que se ponía en duda su significado histórico ${ }^{10}$. En este sentido, entre las primeras noticias sobre la existencia de inscripciones romanas se encuentran las aportadas por Henao en 1689 en su obra Averiguaciones de las Antigüedades de Cantabria (libro 1, cap. XXXX, 123-131), donde menciona un epígrafe en Vizcaya (Axpolueta, «en el camino de Bilbao a Gatíca») y otro en Álava, situado en la iglesia de Urbina de Basabe (CIL II, 2921) ${ }^{11}$ (Fig. 1). Su breve comentario sobre la localización original del ejemplar alavés ${ }^{12}$ fue interpretado por Prestamero como una referencia a su origen fuera del territorio vasco que el presbítero asocia, en el contexto historiográfico del momento, con la negación de la presencia romana, que algunos escritores defendían en sus manuscritos (González de Chávarri, 1900: 276-277). Su crítica parece indicar que este tipo de explicación, que se documenta con cierta frecuencia en escritores posteriores, constituía ya en este momento un argumento habitual con el que sustentar la no dominación del País Vasco. Una argumentación similar había sido utilizada por Moret en relación con unos epígrafes localizados en Fuenterrabía (Guipúzcoa). En su obra De obsidione Fontirabiae libri tres, publicada en 1655 , el jesuita navarro menciona la presencia de unas inscripciones romanas en la casa y el solar de los Casadevantes, lo que «probaba su población en tiempos de los romanos» (Henao, 1689: 123). Sin embargo, en un trabajo posterior corrige su información advirtiendo, que estas habían sido traídas por mar desde Cádiz por lo que no debían considerarse de origen local ${ }^{13}$. La ausencia de datos y el silencio

10. Como es lógico pensar, la admisión de estas tesis tuvo repercusiones claras en la valoración de los restos romanos. Uno de los problemas que plantea la aparición de los epígrafes romanos se encuentra en el hecho de que las dedicaciones a los dioses Manes y a otras divinidades paganas ponían en duda la existencia del monoteismo primitivo y la evangelización temprana de esta región.

11. En Guipúzcoa no menciona ninguna inscripción, ni siquiera la de Oyarzun conocida desde 1470 (Michelena, 1956: 82-83). En su texto se limita a comentar las noticias de Moret sobre la posible existencia de inscripciones romanas en la casa de los Casadevantes en Fuenterrabía (Moret, 1655). Respecto a la inscripción de Axpolueta, Hübner la incluye en el Corpus entre las falsas (CIL II, 243*).

12. «...llevose allí por su antigüedad de parte ahora ignorada», Henao, 1689: 130-131.

13. Moret, 1766: 16 y 17: «Pero estamos ya con toda seguridad enterados, que estas piedras son peregrinas, traídas de Cádiz por Mar, no muchos años ha. Lo qual advertimos, porque nadie tropieze en ellas...». 


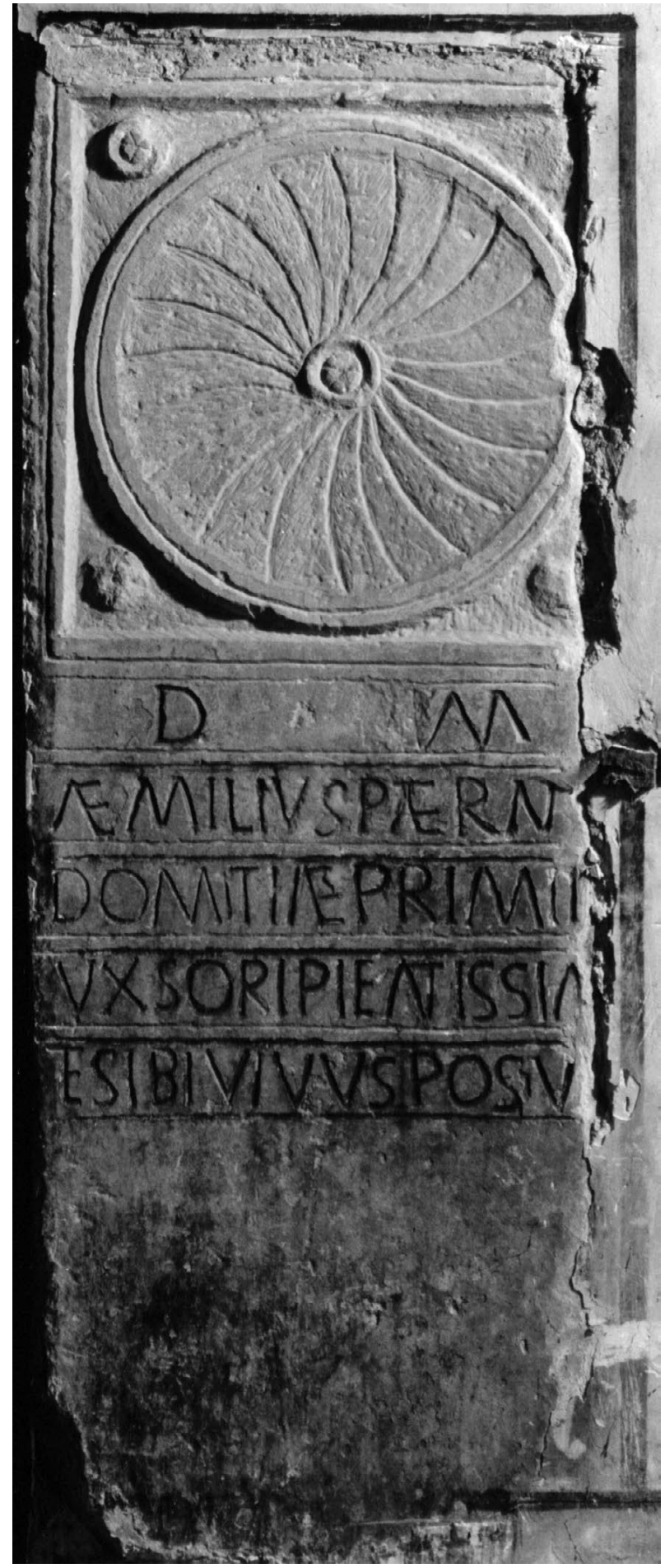

Figura 1: Inscripción de Urbina de Basabe (Álava), CIL II 2921.

posterior sobre su paradero, nos impide despejar la posible interferencia del pensamiento vascocantabrista sobre su procedencia (Larrañaga, 1998-1999: 161-162, n. 69). La rectificación de Moret evoca la crítica de Prestamero - repetida posteriormente por Baraibar- sobre la atribución de un origen foráneo para explicar el hallazgo de materiales romanos. Esta argumentación, que sustenta la concepción de un País Vasco no sometido por Roma, descansa sobre esta misma idea: si los romanos no se asentaron en su territorio, en consecuencia, no pudieron dejar vestigios de su presencia ${ }^{14}$.

A lo largo de los tres siglos posteriores a la publicación de Henao, el volumen de testimonios epigráficos crece considerablemente a partir de finales del s. XVIII y a lo largo del XIX y comienzos del $\mathrm{XX}$. Sin embargo, este aumento no fue un obstáculo para los partidarios de las ideas vascocantabristas, lo que provocará que el avance en un conocimiento de la Antigüedad basado en las fuentes esté acompañado de fenómenos de reacción, como los protagonizados, por ejemplo, por Landázuri y Ortiz de Zárate a finales del siglo XIX y principios del XX. Ahora bien, ante la imposibilidad de negar la existencia de vestigios romanos, los defensores de la independencia del país se verán obligados a modificar su discurso para adaptarlo a una realidad histórica, que cada vez es más evidente. De este modo, desde una interpretación menos «negacionista», se desarrolla la imagen de una dominación incompleta del territorio. La presencia mayoritaria de los restos arqueológicos y epigráficos en Álava frente a las otras provincias hace que la escasez documentada en Vizcaya y, especialmente, en Guipúzcoa contribuya a sustentar la idea de que, a diferencia de la primera, en estas últimas el sometimiento a Roma apenas se había producido. Así, por ejemplo, Labayru, quien en 1895 publica una Historia General del Señorío de Vizcaya donde critica las ideas vascocantabristas desarrolladas por Ortiz de Zarate (1866) en su trabajo sobre Álava, reconoce que esta y Navarra presentaban una situación distinta a la de Vizcaya y Guipúzcoa (Labayru, 1895: 53) ${ }^{15}$, argumentando que «la falta de restos como puentes, caminos, edificios, muros, columnas, y el no haber perdido su fisonomía el bizcaíno, es una prueba de que no se halló supeditado a Roma como otros pueblos y por eso no se introdujo en esta tierra apartada la civilización del Tiber, ni su legislación, hábitos, costumbres, idioma y religión» (Labayru, 1895:55). Tras esta rotunda afirmación, Labayru se centra en los vestigios hasta este momento conocidos, considerándolos problemáticos e insuficientes para deducir el control por parte de Roma de «los abruptos montes y exiguos valles bizcainos». De este modo al referirse en concreto a la inscripción de Meacaur de Morga, publicada en el CIL II 2928, Labayru (1895: 55, n. 3) (Fig. 2), considera la posibilidad de que esta hubiera sido trasladada «de otro

14. En este empeño por eliminar la huella de Roma algunos autores llegan incluso a silenciar importantes descubrimientos arqueológicos, como el de las minas de Arditurri en 1804 (Oyarzun, Guipúzcoa) (Thalacker, 1883; Izaguirre, 1971).

15. Según Labayru en Guipúzcoa el dominio de Roma se habría limitado a la zona del litoral de Oyarzun, donde habían aparecido una estela y algunos restos mencionados por Ceán Bermudez (Labayru, 1895: 56). 
lugar fuera del país basco por capricho ó por aficiones de alguno á las antigüedades» ${ }^{16}$.

En este contexto sobre la verdadera procedencia de los restos romanos, en 1906 Alzola, correspondiente de la Real Academia de la Historia, se lamenta del escaso valor que los historiadores habían dado a las noticias de «algunos publicistas» sobre la aparición de inscripciones romanas en Vizcaya. El descubrimiento ese mismo año en la localidad de Forua de un ara dedicada a Iuilia (HAEp 229) (Fig. 3) constituye para Alzola una prueba irrefutable de la civilización romana en estas tierras, concluyendo que, aunque sus restos fueran escasos, no podía negarse su presencia «mirando las cosas con la debida imparcialidad» (Alzola, 1906: 513 y 515). Este hallazgo y el desinterés mostrado durante años por los restos romanos, le llevó a reivindicar la necesidad de revisar todas las referencias existentes. Así dos años más tarde instó a la Comisión de Monumentos de Vizcaya, de la que era miembro, a iniciar una serie de trabajos destinados a comprobar la veracidad de todas ellas comenzando por las recogidas por Iturriza (Alzola, 1908) ${ }^{17}$. Este autor en su Historia general de Vizcaya (1885) había aludido a la aparición en 1770, durante la reconstrucción de la ermita de San Esteban en Morga (Vizcaya), de varios epígrafes de los que solo se habrían conservado dos, habiendo sido los demás reutilizados de nuevo en la cimentación del edificio (Iturriza, 1885, 410) ${ }^{18 .}$ Alzola en su escrito propone a la Comisión

16. Labayru, 1895: 54-55: «Por el espíritu aventurero de los bizcainos estos escasos objetos han podido importarse de otros lugares por los «muchos marinos, caballeros y letrados que produjo Bizcaya y que vivieron largos años fuera de su patria, hasta que en edad muy avanzada...regresaron a sus solares...Entre tantos hijosdalgo bizcainos que en España y fuera de ella figuraron honrosamente, es de presumir que no faltarían amadores de antigüedades que las adquirieron y las trajeron para esplendor y adorno de sus casas-torres y palacios, sin que el hallazgo casual...signifique nada de lo que se pretende».

17. En 1908 P. de Alzola solicita a la Comisión de Monumentos que investigue y estudie los otros restos de inscripciones de los que se tienen noticias, poniendo en pie de esta forma el compromiso adquirido con la Real Academia de activar el estudio de los restos romanos en la provincia (Alzola, 1906). En relación con esta propuesta, Taracena y Fernández Avilés (1945: 26) dicen que los restos romanos en Vizcaya son «tan pocos, que la Comisión de Monumentos de Vizcaya -región en la que se hace sentir aún más esta falta- se propuso explorar metódicamente los restos que pudieran haber de calzadas y mansiones de aquellos tiempos (Boletín I, cuaderno III, 1909, 11 o II), único criterio acertado para llegar a una conclusión en cosa tan incierta como es el trazado de las antiguas vías y la atribución de los lugares antiguos a los modernos y obra que debe hacerse reposadamente y por conocedores del país para acreditar los resultados, con frecuencia hipotéticos que hasta ahora se han dado a conocer».

18. Defensor también de las teorías vascocantabristas y del no sometimiento de las provincias vascas.

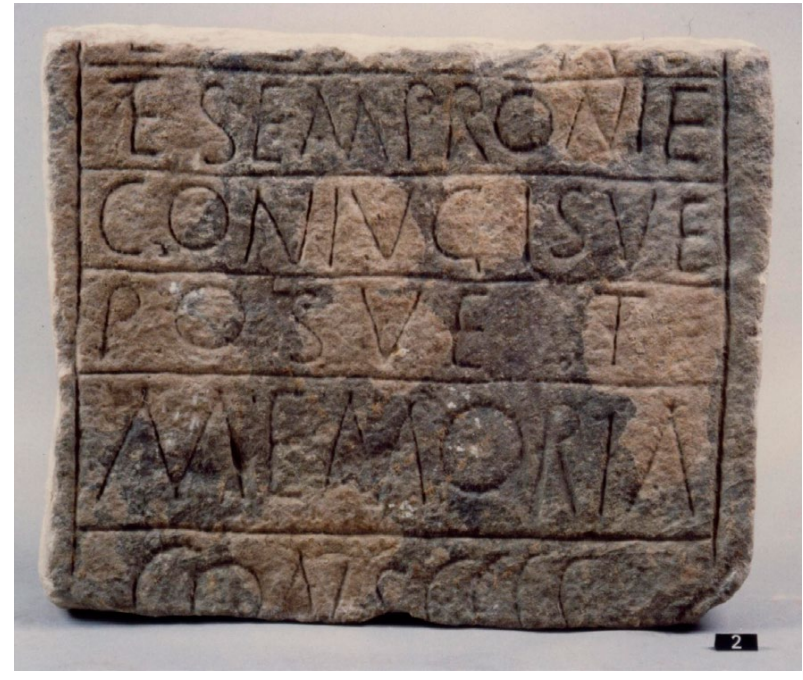

Figura 2: Inscripción de Meacaur de Morga, CIL II 2928. Foto Museo Diocesano de Arte Sacro, Derio (Vizcaya).

investigar en los cimientos de dicha ermita ${ }^{19}$. Aunque su propuesta fue aceptada, los trabajos no llegaron a efectuarse hasta años más tarde (Taracena y Fernández Avilés, 1945: 28-30 ${ }^{20}$.

En Álava el volumen de hallazgos se hace evidente desde la publicación en 1802 del Diccionario Geográfico-histórico y a lo largo de todo el siglo XIX, con los materiales arqueológicos y epigráficos que irán descubriéndose en Iruña y en otras localidades. Aunque es imposible negar estas evidencias y las consecuencias que de ellas se derivan, sin embargo, no faltan autores que adoptan ante ellas una posición más ideológica y política que histórica. Tal vez el ejemplo más llamativo lo encontramos en la figura de Ortiz de Zárate, quien se constituye en una época bastante avanzada del siglo XIX en el defensor de los viejos dogmas. Con una obra titulada Jamás los romanos conquistaron completamente a los vascongados y nunca estos belicosos formaron parte integrante del Imperio de los Césares (1866), en clara defensa de los fueros y con un discurso basado en la independencia del país, Ortiz de Zárate vincula los restos romanos hallados en Álava con el recorrido de la via $X X X I V$, a la que atribuye un carácter militar. Para él es precisamente este carácter, junto a la ausencia de grandes monumentos asociados a la dominación romana, el que confirma la independencia del País Vasco, despreciando «la opinión de aquellos

19. La proposición de investigar en los cimientos de la ermita aparece recogida en el Boletín de la Comisión de Monumentos de Vizcaya, I, cuaderno I, 1909, 44.

20. No fue hasta 1945 cuando Taracena y Fernández Avilés (1945: 28 n.70), retomando la información, dan cuenta de la realización de una serie de catas tanto en la ermita de San Esteban y sus alrededores como en la propia Morga sin obtener resultados satisfactorios. Una situación similar se habría producido en Navarniz, donde en 1814 se habrían encontrado «algunas piedras con inscripciones» (Echegaray, 1921: 349 n. 108; Taracena y Fernández Avilés, 1945). 


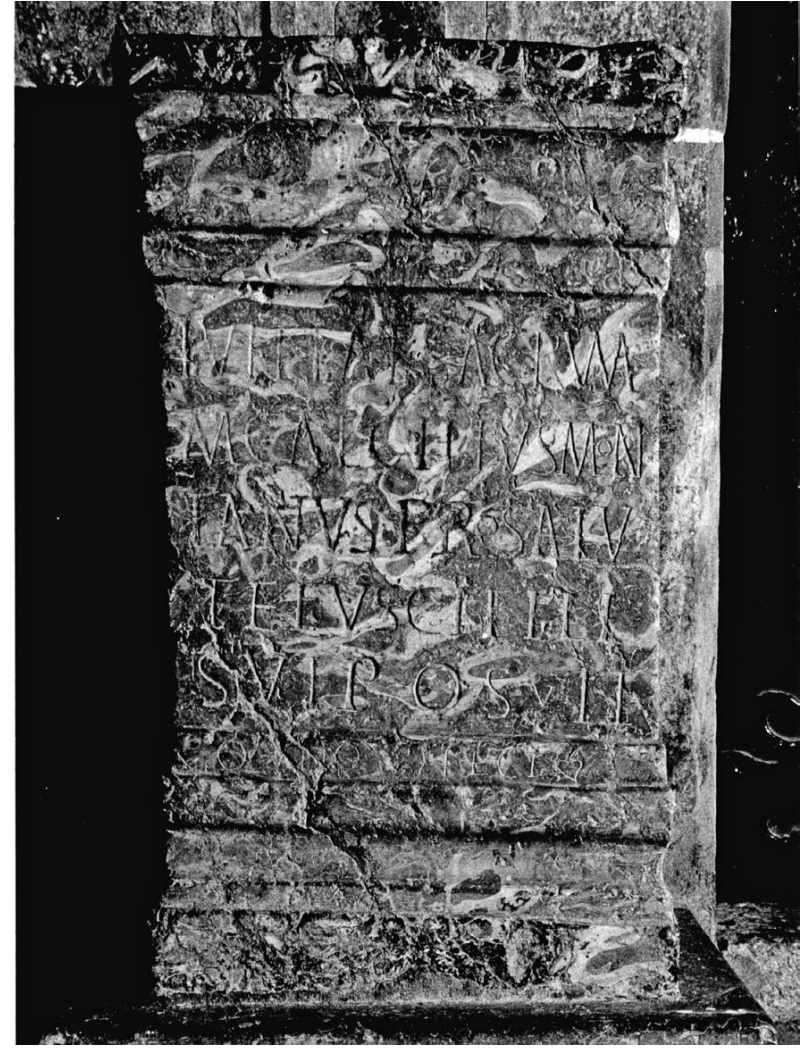

Figura 3: Ara procedente de Forua (Vizcaya), HAEp 229.

que dicen que este país fue completamente conquistado; porque se han encontrado en él algunas medallas, estatuas, lápidas y otras antigüedades romanas» (Ortiz de Zárate, 1866: 57) ${ }^{21}$.

Esta infravaloración de los restos, llega a provocar situaciones tan incongruentes como las que se reflejan en la revista Euskal-erria (1883) y en el volumen correspondiente a la provincia de Álava del Catálogo monumental de España (Castro, 1915). En los dos casos curiosamente se parte de los trabajos elaborados por Baraibar. Como hemos mencionado al inicio de este apartado, el catedrático vitoriano en su discurso impartido en El Ateneo en 1882, tras criticar a aquellos autores que afirmaban la procedencia foránea de los epígrafes y exponer los testimonios romanos en la provincia, concluye diciendo: «no cabe, pues, negar la presencia en los llanos alaveses de un pueblo de quien, al cabo de diecinueve siglos, quedan tantos vestigios y señales» (Baraibar, 1883: 7). En 1883 la revista Euskal-erria publica una reseña de su intervención bajo el título «Variedades Euskaras», en la que, acorde con el nuevo discurso, relativiza la presencia

21. Para Ortiz de Zárate los cántabro-vascongados fueron vencidos pero no subyugados (Ortiz de Urbina, 1996). En 1866, cuando se publica su obra, ya se habían descubierto nuevos epígrafes en la provincia, que serán editados por Hübner en el CIL II. Ese mismo año Janer lleva a cabo trabajos de excavación en Iruña, que sacarán a la luz diversos materiales. romana atribuyendo al profesor vitoriano la siguiente valoración: «El Sr. Baraibar terminó su notable conferencia estableciendo en vista de la escasez de restos romanos existentes en Álava, así como de otras consideraciones etnográficas y filológicas, que los romanos, si bien ocuparon militarmente algunos puntos de esta provincia, se limitaron a conservar expeditas las comunicaciones por sus vías militares, sin internarse en el País Vasco, que les ofrecía escasos productos tributarios en comparación de las fértiles comarcas que por tanto tiempo dominaron» (1883: 155). Igual de sorprendentes resultan las reflexiones recogidas por C. de Castro en el Catálogo monumental de Álava, para cuya elaboración había utilizado también los escritos de Baraibar, entre los que figuraba El Museo incipiente ${ }^{22}$. Castro (1915: 29 y 42) hace hincapié de nuevo en el carácter militar de la via $X X X I V$ como único vestigio de una civilización romana, que no habría dejado ni una sola obra que indicara dominación-templos, acueductos, termas o puentes-a pesar de conocer las ruinas de Iruña y detallar algunos de los materiales allí encontrados (inscripciones, estatuas, etc.).

Así pues, en el País Vasco el interés por la epigrafía romana, por los hallazgos y su estudio, ha estado condicionado en parte por el desarrollo de una historia al servicio de determinados intereses políticos. Sin embargo, el mantenimiento de algunos mitos dentro de un discurso que, con el progresivo descubrimiento de nuevos restos romanos tuvo que ser remodelado para ser creíble, generó a lo largo de estos siglos la reacción de historiadores e intelectuales vascos y foráneos, que reivindicaban un mayor interés por las fuentes materiales y un método más científico, que permitiera la realización de una historia crítica del País Vasco en la Antigüedad.

\section{LA EVOLUCIÓN DE LOS ESTUDIOS SOBRE LA EPIGRAFÍA ROMANA}

Esta concepción ideológica de la historia no impide el desarrollo de trabajos que permiten avanzar poco a poco en el conocimiento de la época antigua en el País Vasco y con ella de la epigrafía romana. Los autores que más han contribuido a este desarrollo forman parte de una élite intelectual compuesta por individuos pertenecientes o relacionados con las capas sociales

22. Castro conocía también la obra de Amador de los Ríos (1871, vol. 21: 23-29), quien se había mostrado crítico con las interpretaciones subjetivas que se hacían de las fuentes en función del interés ideológico del investigador. A pesar de considerar que estaba equivocado en su valoración de las ruinas de Iruña, debido a la influencia de F. Janer, utiliza su información en la elaboración del catálogo, donde se limita a describir ocho epígrafes y señalar la existencia de cuatro fragmentos más descubiertos por Verástegui en Iruña (1915: $30)$. 
más altas ${ }^{23}$. Se trata de personas con una formación humanística, interesadas en la historia y en el conocimiento de la Antigüedad, generalmente vinculadas a instituciones o entidades científicas y culturales vascas, locales, y/o nacionales, como la Real Sociedad Bascongada de Amigos del País, la Real Academia de la Historia, las Comisiones de Monumentos, los museos o la Universidad ${ }^{24}$. Hasta aproximadamente los años cuarenta del siglo XX -e incluso hasta nuestros díasla actividad epigráfica aparece casi exclusivamente asociada a grandes proyectos originados fuera del País Vasco y que, por lo tanto, superan las dimensiones espaciales del mismo, como son la realización del Diccionario Geográfico Histórico de la Real Academia de la Historia o la confección del Corpus Inscriptionum Latinarum $^{25}$. Estas obras, en las que los investigadores vascos participan fundamentalmente como informadores, van a estimular el interés por los trabajos de recopilación, revisión y descubrimiento de nuevos epígrafes. En el siglo XX y tras del parón que supone la Guerra civil, los estudios sobre epigrafía reaparecen ahora de la mano de investigadores vinculados con la Universidad, los museos y los centros dependientes de instituciones provinciales o locales.

\subsection{El DicCionario GeOGRÁFICO-HISTÓRICO Y La LA- BOR DE la Real Sociedad Bascongada de Amigos DEL PAÍs.}

En un panorama historiográfico en el que predominan los viejos dogmas se produce la publicación en 1802 del volumen correspondiente a las «Provincias Vascas y Navarra (Comprende el reino de Navarra, Señorío de Vizcaya y provincias de Álava y Guipúzcoa)» del Diccionario Geográfico-Histórico de España elaborado por la Real Academia de la Historia. En él encontramos recogidas, por primera vez, casi la totalidad de las inscripciones romanas conocidas hasta este momento en el País Vasco, en su mayor parte procedentes de

23. A lo largo de todo este tiempo encontramos miembros de la nobleza, militares, personas encargadas del gobierno y la administración provincial, profesores vinculados con la enseñanza, ingenieros, etc.

24. Entre las entidades científicas y culturales vascas hay que mencionar también la Sociedad de Estudios Vascos-Eusko Ikaskuntza y entre las locales El Ateneo vitoriano. Los estudiosos más destacados aparecen, a su vez, vinculados a las Reales Academias de la Historia y de San Fernando, en unos casos como miembros, en otros como correspondientes. Vid. infra.

25. Habría que añadir a estos el proyecto para estudiar los caminos romanos en España en el que participaba J. Cornide y con el que hay que vincular los trabajos sobre la via XXXIV a su paso por Álava. Un impulso fundamental en el estudio de los restos epigráficos en los últimos veinte años del siglo $\mathrm{XX}$ lo constituyen el proyecto de revisión del CIL y el programa PETRAE.
Álava ${ }^{26}$. Su aparición supuso un avance hacia una historia más crítica y objetiva, que provocó la reacción de los sectores intelectuales más «extremos». Estos hicieron una lectura política de la obra (Mañaricúa, 1973), en la que los ataques no estaban dirigidos tanto hacia los informadores como hacia los encargados de redactar las distintas voces. En la recopilación de fuentes desempeñó un papel destacado la Real Sociedad Bascongada de Amigos del País a través de algunos de sus miembros, especialmente, de aquellos vinculados con Álava. A pesar de su posición ambigua respecto al problema del vascocantabrismo (Larrañaga, 19981999; Duplá y Cortadella, 2014), la preocupación por las cuestiones metodológicas despierta su interés por la recopilación de las fuentes arqueológicas y epigráficas para el estudio de la Antigüedad. Es bien conocida la afición de algunos de sus miembros hacia los temas histórico-arqueológicos, que, por otro lado, concuerda con el ambiente cultural existente en España durante el siglo XVIII, donde destaca la preocupación por los testimonios relacionados con la civilización romana. De hecho, sus socios más destacados no se mantuvieron aislados de la actividad cultural desarrollada fuera del País Vasco, llegando a formar parte de las Academias españolas de la Historia y de San Fernando ${ }^{27}$. Aunque en este momento la presencia de restos romanos en el País Vasco no era muy relevante, la Bascongada no descuidó este campo, convirtiéndose prácticamente en la iniciadora de los trabajos arqueológicos que a partir de ahora van a ir desarrollándose (Ortiz de Urbina, 1996: 47-71). Como se recoge en el Prólogo del volumen del Diccionario dedicado al País Vasco y Navarra, bajo la iniciativa del Conde de Campomanes se elaboró un plan y un método de trabajo, en el que se contaba con la colaboración de los académicos correspondientes, los gobernadores y los prelados de las provincias. Estos debían enviar una descripción de su provincia incluyendo los datos históricos, entre los que se hallaban noticias sobre «vestigios, ruinas o rastros de antigüedad. Lápidas, inscripciones o medallas...». En el contexto de esta labor se sitúan los contactos que el Director de la Academia mantiene con socios de la Bascongada. Si bien la base de las informaciones de cada uno de los territorios se debe a la colaboración de distintos eruditos vinculados estrechamente con el País

26. Treinta y tres inscripciones en Álava, dos en Vizcaya y la mención sin texto de la lápida de Oyarzun en Guipúzcoa.

27. Personajes como J. M. ${ }^{a}$ de Munibe, Conde de Peñaflorida, director de la Sociedad o su sucesor en el cargo J. M. ${ }^{\text {a de }}$ Aguirre, Marqués de Montehermoso, formaban parte también de las Academias españolas de la Historia y de San Fernando. Otros como P. J. de Álava era honorario de la Academia de la Historia o L. del Prestamero llegó a ser correspondiente de la misma. La relación entre estas instituciones se materializó también en el nombramiento como socios de la Bascongada de individuos pertenecientes a la Academia, como, por ejemplo, J. Cornide. 
$\operatorname{Vasco}^{28}$, la redacción definitiva de las distintas entradas del Diccionario se distribuye entre los miembros de la Junta permanente creada en $1799^{29}$.

En el caso de Álava, la edición del Diccionario significa la publicación de los resultados obtenidos en un trabajo iniciado años antes, en el que participaban el marqués de Montehermoso, P. Jacinto de Álava y L. del Prestamero, que se extenderá también al campo de las antigüedades y entre ellas al de la epigrafía ${ }^{30}$. De todos ellos es Prestamero (1733-1817) el que nos interesa de forma especial, porque es a él a quien se atribuye el estudio de los testimonios epigráficos alaveses durante este período. Educado en Vitoria y Salamanca, en el año 1770 fija su residencia en Vitoria y entra a formar parte de la Sociedad Bascongada en 1771, donde diez años más tarde llegó a ocupar los cargos de vicesecretario y archivero $^{31}$. Su actividad se hace especialmente notoria cuando se traslada la sede de la Bascongada a Vitoria, tras la muerte del conde de Peñaflorida en 1785 y el nombramiento del marqués de Montehermoso como nuevo director. Durante su vinculación con la Sociedad, Prestamero desarrolló su trabajo en múltiples campos, destacando su interés por el estudio de la historia en general y de las antigüedades, lo que le llevará al terreno de la epigrafía y la arqueología ${ }^{32}$. Consecuencia de esto serán los dos tomos en folios de inscripciones antiguas y modernas de Álava, citados por Humboldt al narrar su estancia en Vitoria ${ }^{33}$.

Los documentos manuscritos conservados en el Archivo del Territorio Histórico de Álava (A.T.H.A.),

28. Así para Vizcaya se utiliza la Historia General de Vizcaya escrita por J. R. Iturriza y enviada a Campomanes en 1786 -cuya información es revisada posteriormente por L. Marcelino Pereyra- y para Álava los informes transmitidos por P. J. de Álava desde 1785 auxiliado por L. del Prestamero (Diccionario, Prólogo: XXIX-XXX).

29. De este modo F. Martínez Marina, en ese momento director de la Real Academia, se encargará de la provincia de Álava y V. González Arnao de Vizcaya; J. Taggia y M. Abella lo harán de Navarra y Guipúzcoa se reparte entre los cuatro (Diccionario, Prólogo: XXIII-XXIV).

30. Este trabajo tiene su origen en una junta semanal de los socios de Álava celebrada el 7 de enero de 1776, en la que se había acordado recoger las noticias geográficas referentes a la provincia (Urdiain, 1985).

31. El traslado del Archivo General a Vitoria en 1785 hizo que Prestamero se encargara de él (Urdiain, 1985: 80).

32. Urdiain, 1985: 79. En su trabajo como epigrafista se centra no solo en las inscripciones romanas sino también en las modernas tal y como se aprecia en los manuscritos conservados en el A.T.H.A. En el campo de la arqueología destacan las excavaciones efectuadas en la villa romana de Cabriana.

33. En 1799 Humboldt menciona en su diario a Prestamero a quien define como un erudito y meritorio sacerdote a cuya gentileza debe el investigador muchas noticias interesantes sobre todo del idioma vasco. De su actividad señala el trabajo de recogida de materiales realizado durante bastantes años para llevar a cabo una descripción de Álava, que deberá remitir la Academia de la Historia para la redacción del Diccionario (Santoyo, 1972: 207-208). muestran que su actividad epigráfica ya se había iniciado en 1774, cuando recoge algunas notas sobre la iglesia de Armentia -donde dos años más tarde saldrá a la luz la mitad de una inscripción romana (CIL II, 2938), de la que hará una copia-, prolongándose, al menos, hasta 1804 con el estudio de las inscripciones aparecidas en Vizcaya ${ }^{34}$. A lo largo de todo este tiempo irá reseñando los epígrafes procedentes de distintas zonas de la provincia, como Iruña (en su mayor parte localizados en la ermita de Donela y en la Iglesia del Priorato de la Orden de San Juan), San Román de San Millán, Contrasta, Cabriana, etc. ${ }^{35}$ En esta recopilación colaborará también el Marqués de Montehermoso, con quien realiza una visita a la iglesia de Urbina de Basabe el 11 de mayo de 1785, para copiar la inscripción que había recogido Henao en sus Averiguaciones. Lamentablemente muchos de estos epígrafes, en especial los procedentes de Iruña, han desaparecido sin que hayan quedado más datos que los aportados por Prestamero. En 1799 se produce el contacto directo de este con la Academia, tal y como parece confirmar el prólogo del Diccionario, en el que se agradece expresamente su colaboración auxiliando a Jacinto de Álava, cuando la Junta le encargó que completase la descripción de las 36 hermandades que faltaban, trabajo que le valió el nombramiento como socio correspondiente ${ }^{36}$. Fue él, según se indica, quien remitió la información solicitada y algunas noticias «muy útiles» sobre la denominada via XXXIV De Hispania in Aquitania ab Asturica Budigalam copiando muchas de las inscripciones existentes a lo largo de ella. Todos estos datos forman parte de un estudio titulado Camino militar romano que pasaba por Álava ${ }^{37}$, cuya realización parece ser fruto de investigaciones iniciadas posiblemente por J. de Álava y a las que Prestamero añade los hallazgos que se van produciendo.

Respecto a su trabajo como epigrafista no disponemos de más información, que la que se desprende del análisis de sus escritos. Por lo que se aprecia en los manuscritos Prestamero efectuaba en su estudio más o menos sistemático un análisis directo de los materiales $^{38}$, desarrollando una labor de campo que incluía una copia de cada uno de los monumentos, primero

34. Carpeta de manuscritos. Archivo Histórico-Documental de la Diputación Foral de Álava, DH-1080-30; DH-1299-2.7. 35. Ibidem, DH- 1080 y 1299.

36. Diccionario, Prólogo, p. XXIX. La correspondencia mantenida con J. Cornide, miembro de la Academia e implicado en la realización del Diccionario y de un estudio sobre las vías romanas de la Península con el que se relaciona el Camino militar de Prestamero, documenta también esta participación. Ortiz de Urbina, 1996, 81 y ss. con referencias a los documentos del Archivo de la Real Academia de la Historia (A.R.A.H.)

37. De este estudio parece que habrían existido cuatro manuscritos (Ortiz de Urbina, 1996, 99).

38. Existe alguna excepción que él mismo indica como la inscripción de Assa que mandó copiar al presbítero de Abásolo. 
mediante un boceto y después a través de un dibujo en el que intentaba reproducir el texto así como su estado de conservación. Junto a él anotaba distintos datos sobre la localización y, en algunas ocasiones, las dimensiones e incluso la altura de las letras, el estado de conservación y algunas características externas, añadiendo por último la fecha -o las fechas- de la autopsia. Todos estos elementos le sirven de base para la elaboración de los informes que envía a la Academia y las descripciones que hallamos en el Diccionario y el Camino militar. Aunque en términos generales se puede decir que la información presente en toda la documentación coincide, el objetivo de estas dos obras hace que en ellas estén ausentes datos referentes a las medidas y a las características del monumento ${ }^{39}$. La mayor concreción de la segunda, centrada en la provincia de Álava en época romana, le lleva a valorar algunos epígrafes incluyendo, junto a la traducción del texto, algún comentario histórico, incluso onomástico, no siempre acertado ${ }^{40}$. En el caso del Diccionario, donde la redacción definitiva de las distintas voces no es obra de Prestamero, no es posible establecer con seguridad si las observaciones detalladas, que en él encontramos, o la corrección de las lecturas son obra suya o del encargado de la composición del texto. Así sucede, por ejemplo, con la inscripción de Assa (CIL II, 2923), de la que en el manuscrito conservado en el A.T.H.A. no hay ninguna referencia a la lectura hecha en la España Sagrada del padre Flórez, que sí aparece criticada en el Diccionario (Real Academia de la Historia, 1802, 123). En el epígrafe de Urbina de Basabe tampoco encontramos ninguna alusión a la interpretación hecha por Henao, limitándose la información a señalar que fue copiada exactísimamente por el marqués de Monterhermoso y por él mismo ${ }^{41}$.

En lo que se refiere a sus lecturas, solo podemos comprobar su corrección en los monumentos que se han conservado hasta hoy. Consciente de su limitada

39. Parece que la información más completa de los monumentos se encuentra en los informes enviados a la Real Academia de la Historia, donde las descripciones contienen datos más precisos sobre el hallazgo, las medidas, etc., que posteriormente no aparecen recogidos en el Diccionario ni tampoco en el manuscrito del A. T. H. A., tal y como se aprecia en las inscripciones de Iruña o la de Urbina de Basabe, por ejemplo.

40. Así en la inscripción procedente de Margarita (CIL II, 2928) comenta: «Marco Octavio Galico ó francés de nación, hijo de Sabino, y de la tribu Quirina: se puede suplir de tantos años de edad, está enterrado aquí. Este Marco Octavio, francés, pudiera ser algún soldado de la cohorte francesa, que en tiempo del Emperador Constantino estaba de guarnición en Veleia, en donde residía el tribuno de la primera cohorte gallica y era en la comarca de los pueblos autrigones, no hacia Nájera, como dijo Morales y Henao, pués por allí iba el otro camino que queda referido» (González de Echávarri, 1900: 304-5)

41. Carpeta de manuscritos. Archivo Histórico-Documental de la Diputación Foral de Álava, DH-1299-2, p. 5 n. ${ }^{3} 3$ y p. 2-3 de otro folio. Real Academia de la Historia, 1802: 409. formación como epigrafista, Prestamero trata de realizar un trabajo riguroso y minucioso en la copia del texto, que se observa especialmente en aquellos epígrafes más problemáticos. En los casos más complicados opta por transcribir las letras que reconoce en espera de que aquéllos que tienen más conocimientos puedan aportar una solución. Esta postura la expresa con claridad al estudiar la lápida $(H A E p, 222)$ procedente de Morga (Vizcaya), donde dice: «La copia estampada en el citado Diccionario fué probablemente sacada por un curioso que de antemano se prometia hallar alli caracteres desconocidos. A mi me pareció un rato que al fin podia querer decir Jesu Salvatori meo, pero poco versado en tales antiguallas me he ceñido a copiar la inscripcion con la mayor exactitud que me ha sido posible, dexando á otros mas doctos el descifrarla $\rangle^{42}$. Teniendo en cuenta la minuciosidad que muestra en su trabajo, cuesta creer, por ejemplo, que Prestamero no haya leído en la inscripción CIL II, 2929=5813 procedente de San Esteban de Treviño (Fig. 4), una sexta línea, situada fuera del campo epigráfico, perfectamente visible en la pieza actualmente depositada en el Museo Bibat (Vitoria) y mencionada por autores posteriores ${ }^{43}$. En otras ocasiones, sin embargo, a pesar de las dificultades que plantea el desgaste o la rotura de la piedra, así como el tipo de letra o su grabado, Prestamero ofrece una lectura, que a él mismo le resulta insólita pero de la que intenta dar una explicación razonada. Así sucede, por ejemplo, en la inscripción de Ilarduya (CIL II, 4903) (Fig. 5) donde transcribe erróneamente las dos primeras líneas, en las que en lugar de $I M P$. FLAV/IO VALERIO CONSTANTIO lee IMPER AU/ LO VALERIO/ CONSTANTIO... Ante la extrañeza que le produce esta nomenclatura imperial concluye: «No sabía que Constantio Chloro tuviese el pronombre de Aulo, que aquí está claro con todas sus letras, así como todo lo demás de la inscripción. Grutero, pág. 192, produjo una de este Emperador hallada en la isla de Gaulo, en estos términos: DN. C. AVR. VALER/ CONSTANTIO. AUG./ R. P. GAUL. CVRANTE/ F. POLLIONE ...RUFO/M. F...IIIVIRR ... Esta inscripción de Grutero está maltratada según se ve por los puntos con que la copio, por lo que se puede sospechar que el $A U R$ de aquella seria $A U L$ como en la presente y que efectivamente, tuvo Constancio el pronombre de $A U L O$ ignorado hasta ahora por los escritores, que yo he visto» (González de Echávarri, 1900, 31314). Una situación similar parece reproducirse en algunas

42. Carpeta de manuscritos. Archivo Histórico-Documental de la Diputación Foral de Álava, DH-1080-30.

43. M(arcus) Porcius / Ausci fi(lius) / Quir(ina) Toni/us an(norum) $L X X V / H$ (ic) s(itus) e(st) //HF E P L. La sexta línea aparece en Baraibar y en el CIL II (5813), donde Hübner escribe en su comentario «qui nouus accesit quid significet non intellego», reconstruyendo la fórmula con un interrogante. Los datos disponibles sobre su ubicación original y su estado de conservación, plantean dudas respecto a la pieza conservada. 


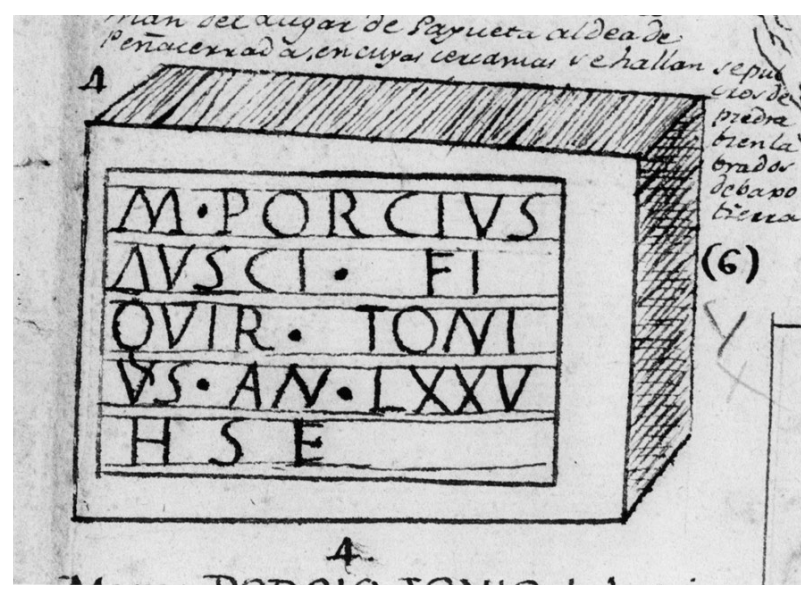

Figura 4: Copia de L. del Prestamero de la inscripción de San Esteban de Treviño, CIL II 2929=5813. Manuscrito depositado en el Archivo Documental de la Diputación Foral de Álava.

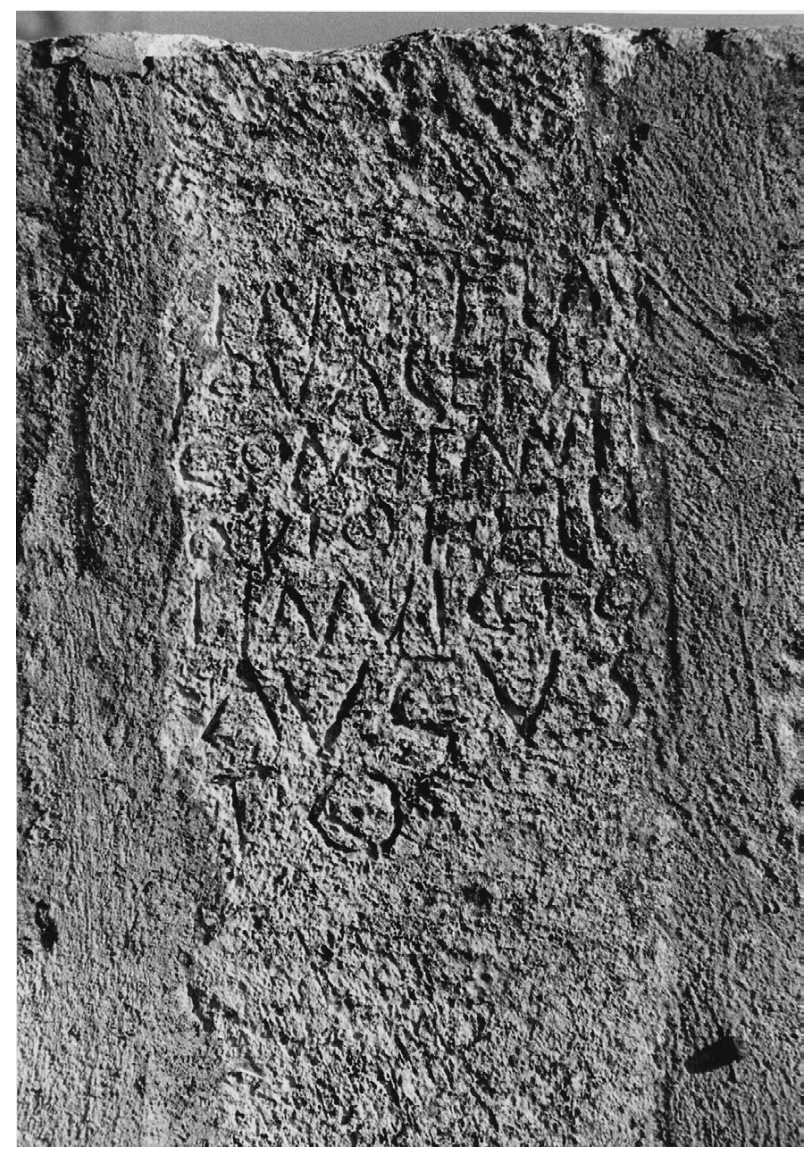

Figura 5: Inscripción de Ilarduya (Álava), CIL II 4903.

de las inscripciones actualmente desaparecidas, en las que la imposibilidad de hacer una nueva autopsia o de contrastar su información con otros testimonios, impide su comprobación. La inscripción dedicada a $V V A R N A$ procedente de Cabriana (CIL II, 2924) se encuentra en este caso. A pesar de las lagunas dejadas por el presbítero al describir su estado de conservación, la mayor parte de los investigadores posteriores han aceptado como cierta una lectura poco segura que él reconstruye, deduciendo a partir de ella la existencia de realidades históricas, que no pueden ser verificadas ${ }^{44}$.

\subsection{LOS AVANCES DEL SIGLO XIX}

En los años posteriores a la muerte de Prestamero los estudios epigráficos se paralizan prácticamente hasta la aparición de F. Baraibar. A lo largo de todo el siglo $\mathrm{X} 1 \mathrm{X}$ las obras que intentan recopilar la epigrafía del País Vasco se limitan a repetir los datos del Diccionario Geográfico de 1802. En este grupo se incluyen, por ejemplo, el Diccionario Geográfico Estadístico de España y Portugal (1826) de S. de Miñano y el Sumario de las antigüedades romanas que hay en España (1832) de A. Cean Bermúdez. Sin embargo en este tiempo no se desvanece el interés por las antigüedades, como documentan los informes enviados a las Reales Academias de la Historia y de San Fernando desde Álava, o los breves artículos publicados en revistas locales como El Lirio (Madinabeitia, 1845; Ayala, 1846). Algunos de los encargados de estos informes están vinculados con el gobierno de la provincia y la presidencia de la Comisión de Monumentos de Álava, entre los que se encuentran Manuel de Arriola, quien en febrero de 1833 comunica a la Real Academia de Bellas Artes la existencia de un cementerio romano en Albéniz del que adjunta dos inscripciones (CIL II, 2948 y 2949) (Ortiz de Urbina, 1996: 141); R. Ignacio de Varona y Salazar, que en octubre 1858 envía un informe a la Academia de la Historia sobre los restos que han quedado de la dominación romana en el valle de Valdegovía, donde junto a la mención de ruinas da cuenta de una inscripción aparecida en Villanañe (CIL II 2922) ${ }^{45}$; y Florencio Janer, miembro del Cuerpo Facultativo de Archiveros y Bibliotecarios, gobernador civil de Álava y reorganizador de la Comisión de Monumentos de la provincia, quien desempeñó una intensa labor arqueológica especialmente en Iruña. Dos informes de la Comisión de Monumentos enviados a las Academias de la Historia y de San Fernando comunican los resultados de sus trabajos, notificando el descubrimiento de tres fragmentos de inscripciones, cuyas características desconocemos ${ }^{46}$.

44. No se trata solamente de la identificación de una divinidad indígena, sino también de la existencia de unos tignarii en la zona.

45. Ortiz de Urbina, 1996: 152 y 313-315. Baraibar, tal vez recogiendo los datos del Corpus, escribe en su manuscrito (ficha Villamaderne) que este informe fue enviado a Fernández Guerra, que a su vez lo dio a conocer a Hübner, quien publicó la inscripción en el CIL II (2922).

46. Un oficio de 31 de octubre de 1866 remite a la Real Academia de la Historia dos fragmentos de inscripciones con un dibujo (ms. 9/7944, A.R.A.H.), uno de los cuales desaparecerá en 1867 en el incendio de las oficinas del Gobierno civil donde había sido depositado el material. La primera, actualmente también desaparecida, estuvo depositada en el museo creado por Baraibar, quien en su guía dice expresamente que el padre 
Pero fue F. Baraibar (1851-1918) el continuador, por decirlo de alguna forma, de la obra de recopilación y estudio iniciada por Prestamero. Su labor se sitúa dentro del ambiente intelectual vitoriano que se desarrolla, especialmente, en la segunda mitad del siglo con la creación de diversas asociaciones culturales y de la llamada Universidad Libre de Vitoria (18691874) (Rivera, 1992; Ortiz de Urbina, 1996: 163 y ss.). La más representativa de todas estas entidades la constituye el «Ateneo Científico, Literario y Artístico de Vitoria», en el que se crea una sección de Historia y Arqueología $a^{47}$ a la que estuvo vinculado Baraibar, quien desempeñó un intenso papel en su desarrollo ${ }^{48}$. Formado en letras clásicas, conocedor de varias lenguas y catedrático de Instituto desde 1876, se interesó no solo por la traducción de obras clásicas griegas, sino también por la investigación en arqueología y en epigrafía, siendo en este último campo donde más destacó su trabajo. El reconocimiento a sus investigaciones le proporcionó el nombramiento como correspondiente de las Reales Academias de la Historia (1883), de San Fernando y de las Buenas Letras de Sevilla, así como corresponsal del Instituto Arqueológico Imperial Alemán de Berlín y Roma. Su interés por la epigrafía se documenta desde 1882, cuando con motivo de la inauguración del curso 1882-1883 pronuncia un discurso en el Ateneo con el título de Antigüedades de Iruña. En él da cuenta de dos epígrafes que considera inéditos e incluye un apéndice donde recoge todas las inscripciones procedentes de Iruña conocidas hasta el momento ${ }^{49}$. Con este trabajo Baraibar inicia una investigación que se desarrollará hasta 1914, fecha en la que

Fita la tenía en estudio (Baraibar, 1912: inscripción n. ${ }^{\circ}$ 2). Con posterioridad un nuevo informe enviado a la Academia de San Fernando con fecha del 1 de diciembre de ese mismo año señala la aparición de otro pequeño fragmento con dos letras, distinto de los anteriores, cuyas características desconocemos (Ortiz de Urbina, 1996).

47. Creado el 14 de abril de 1866 gracias al impulso de una serie de catedráticos de Instituto. En él no sólo se organizan conferencias, discusiones o Juegos Florales, sino que también se imparten cursos, algunos de ellos centrados en la Antigüedad y la arqueología. El Ateneo participará también en eventos internacionales como, por ejemplo, la Exposición de París de 1878. Sobre su historia vid. Reboredo Olivenza, 1988.

48. En el Ateneo, Baraibar ocupó los cargos de secretario (1872$73)$, vicepresidente (1874-75 y 84) y presidente (1876) (Reboredo Olivenza, 1988: 121). Una semblanza sobre su figura la encontramos con motivo de su fallecimiento en la Memoria del curso 1917-1918 del Instituto General y Técnico, donde fue catedrático de latín durante más de cuarenta años y su director desde abril de 1907. Su participación en la vida pública de la ciudad superó el ámbito intelectual siendo alcalde durante cinco años y presidente de la Diputación por un período de más de cuatro años.

49. En esta publicación menciona en nota los dos fragmentos de inscripción (CIL II, 5818 y 5825) procedentes de la ermita de San Pedro de Salásces (Ollávarre) conocidas por Prestamero (González de Echávarri, 1900: 297), pero que Baraibar (1883: 59-60) da como inéditas. publica el artículo «Lápidas de La Puebla de Arganzón y Laguardia». En esta labor el estímulo fundamental lo constituye el encargo hecho por la Real Academia de la Historia para que estudie directamente los epígrafes aparecidos recientemente en Iruña (Fita, 1887). Sus investigaciones a lo largo de estos años superan el marco geográfico de Álava, ampliándose a monumentos procedentes de las provincias limítrofes de Burgos, Navarra, La Rioja y Vizcaya (Baraibar, 1895a; 1895b; 1907; Echegaray, 1921).

La evolución que ha experimentado la epigrafía a lo largo del siglo sitúa a Baraibar en un ambiente diferente al de Prestamero. Aunque la situación en España estaba todavía lejos de la que se documenta en otros países europeos, durante la segunda mitad del siglo XIX se va a ir configurando una epigrafía hispánica relativamente independiente de la tradición historiográfica, siguiendo un proceso impulsado en el siglo anterior por investigadores como Mayans (Gimeno, 2012) y ahora por Hübner (Le Roux, 1984; Stylow y Gimeno, 2004), Paris (Etienne y Le Roux, 1990) o Fita (Abascal, 1996; 1999). La publicación en 1869 del CIL II, que constituye el primer estudio sistemático y científico de la epigrafía romana peninsular (Le Roux, 1984: 18), influirá positivamente en este desarrollo. Siguiendo los principios del positivismo y concebido bajo la influencia del método filológico los criterios utilizados en su confección -revisión de los textos, crítica de las lecturas, utilización y valoración de los manuscritos, datación de los documentos, establecimiento de su procedencia exacta, importancia de la paleografía, utilización de calcos, fotografías, etc.- le confieren un rigor técnico y una especialización vinculados con el desarrollo de las «ciencias auxiliares» que van a contribuir al avance de la Historia ${ }^{50}$. Para la edición de las inscripciones de Hispania Hübner contará con la colaboración de la Real Academia de la Historia y de figuras como A. Fernández Guerra o F. Fita, así como de otros epigrafistas que desde distintas partes le han facilitado información acompañada de calcos y fotografías. Este clima de colaboración con los investigadores alemanes y franceses convertirá a la Academia en una entidad muy activa en el campo de la investigación y de la edición epigráfica, siendo su órgano de expresión el Boletín creado en 1877. En relación con esta actividad hay que citar a F. Fita -director de la Academia desde 1912 y colaborador de Hübner-, quien consiguió establecer una red de corresponsales, entre los que se encuentra Baraibar, quienes mediante un fructífero intercambio epistolar le proporcionaban acceso a todos los hallazgos y

50. Este desarrollo es posible por el clima propicio que ya se venía gestando en Alemania desde principios de siglo tanto a través de la creación de instituciones como la Academia de Berlín (1810), el Instituto Arqueológico de Roma (1829) como de la propia universidad. Sobre el método vid. Le Roux, 1984, 21 y 22. Vid. también Fita, 1887. 


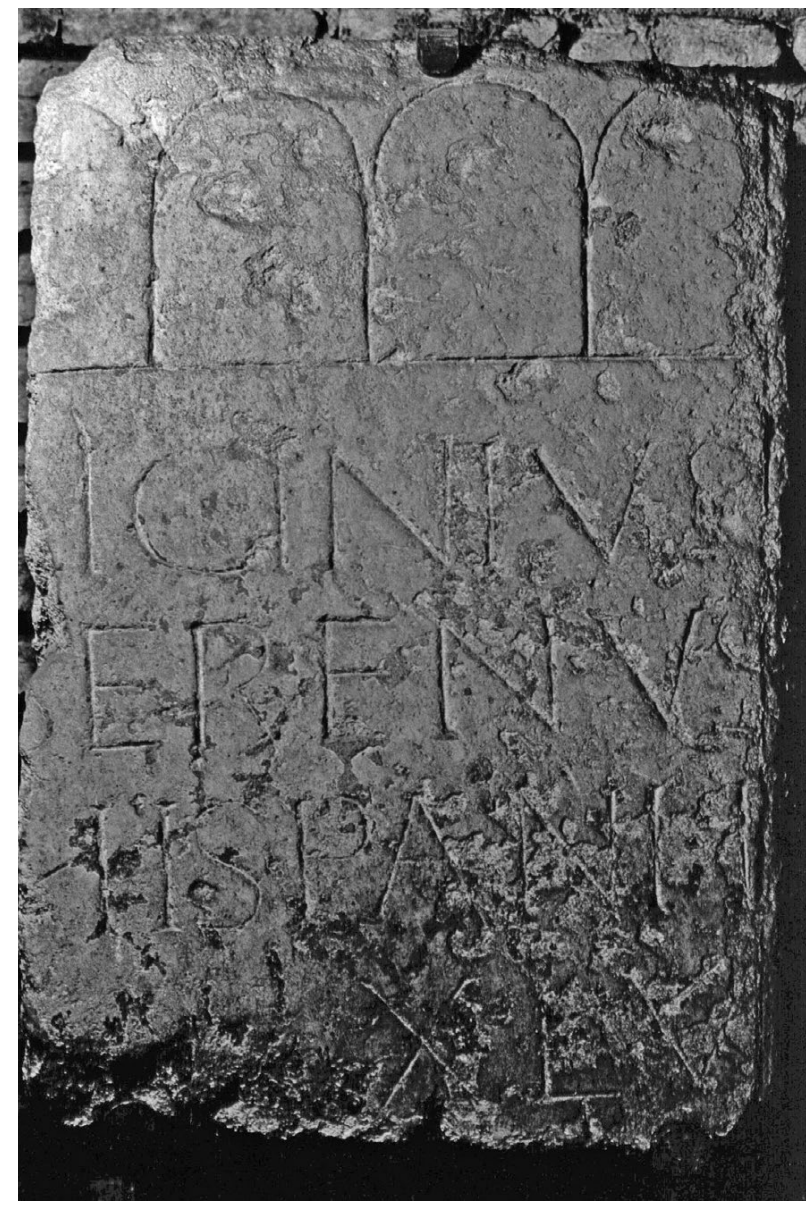

Figura 6: Estela de Licinius Serenus, Iruña (Álava), CIL II 2934. Foto Bibat-Museo de Arqueología. AFA/DFA. Vitoria (Álava).

las novedades que se producían en España sin tener que desplazarse constantemente. La influencia de Fita y del propio Hübner, con quien también mantendrá correspondencia (Albertos, 1970a), determinará las características de la investigación epigráfica de Baraibar. Por lo que se desprende de sus trabajos podemos decir que, en 1882, cuando lee su discurso en el Ateneo, apenas había entrado en contacto con la epigrafía que se estaba realizando en estos momentos. Así parece indicarlo el hecho de que en el apéndice del mismo recoge las inscripciones ya publicadas tomando como referencia el Diccionario Geográficohistórico de 1802 en lugar del CIL II, a excepción de la última para la que cita a Hübner como editor, pero confundiendo el número ${ }^{51}$; del mismo modo da como inédita la estela de Licinius Serenus (Fig. 6) cuando esta ya aparecía publicada en el Corpus con el número 2934, un error del que se disculpa posteriormente en su informe enviado a Fita (1887: 405-6) en 1886. A partir de este informe, en el que todavía manifiesta sus limitaciones, su estudio de las inscripciones aparece

51. Se trata de la inscripción CIL II 2936, que Baraibar (1883) identifica erróneamente con el número 2934.

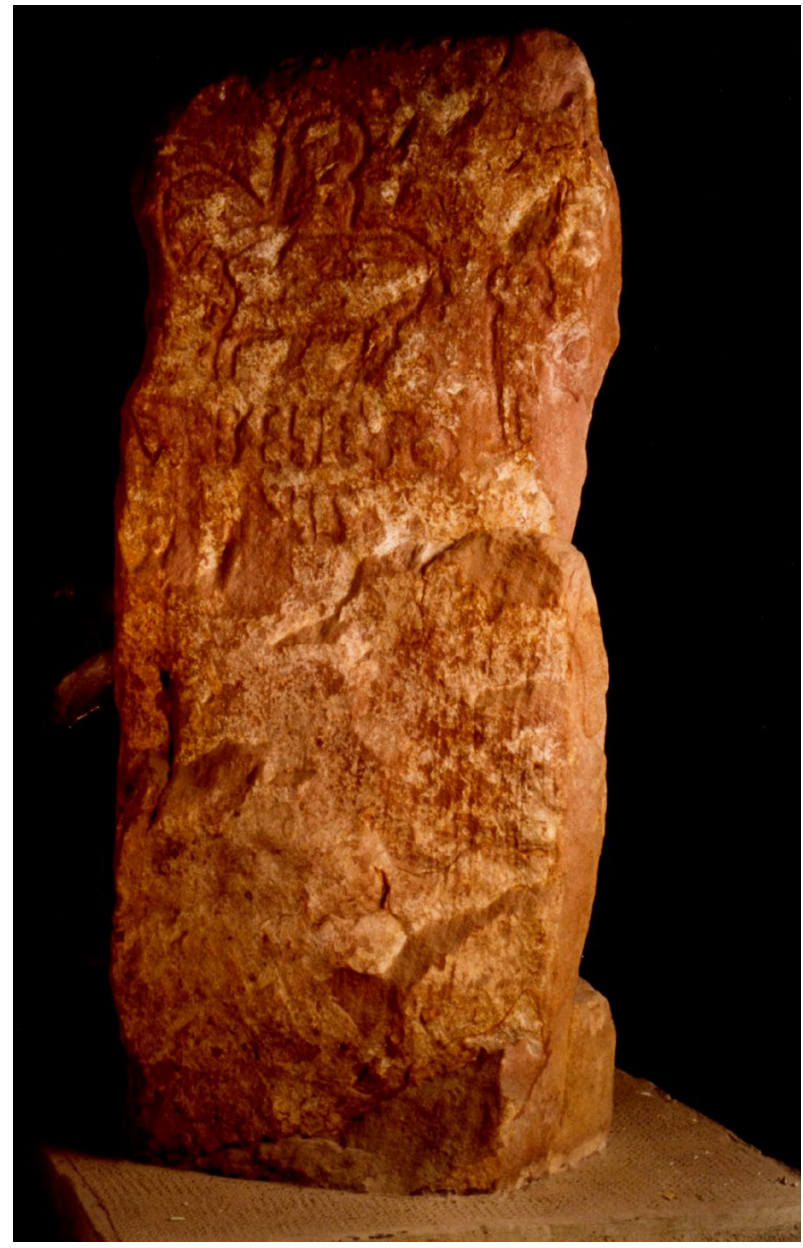

Figura 7: Inscripción de Oyarzun (Guipúzcoa), HAEp 2464. Foto Museo San Telmo, San Sebastián (Guipúzcoa).

elaborado según las pautas de la «ciencia epigráfica», con la publicación de trabajos cuyo objetivo básico es dar a conocer los nuevos hallazgos mediante la inspección directa, la utilización de calcos y fotografías $^{52}$, así como la inclusión de datos sobre el lugar de hallazgo, las medidas, el suplemento de las abreviaturas e, incluso, de un comentario histórico acompañado de una valoración onomástica, etc. Estas mismas características se atestiguan también en su documentación manuscrita ${ }^{53}$, donde Baraibar ha recopilado toda la epigrafía romana de Álava en

52. En la actualidad se conservan algunas de las fotografías pertenecientes a Baraibar tanto en el Archivo Municipal (entre el material de la Comisión de Monumentos de Álava de la que él era vocal) como en el del Territorio Histórico de Álava (Fondo López de Guereñu). Sobre la utilización de calcos, mencionada por Baraibar en distintas ocasiones, nos ha quedado el testimonio fotográfico del realizado a la inscripción (HAEp, 2554) de Narvaja (Álava) antes de que esta fuera rota habiendo desaparecido el texto.

53. En los fondos de la Comisión de Monumentos se conservan varias fotografías de los trabajos de Baraibar entre los que aparecen tres volúmenes perfectamente encuadernados bajo el título de Epigrafía. 
algunos casos acompañada de un comentario personal. Entre este material aparecen, por supuesto, las inscripciones encontradas durante sus trabajos de campo en distintas localidades, algunas de las cuales permanecerán inéditas hasta que J. C. Elorza las publique en 1967. El desarrollo de su trabajo durante los años siguientes se materializará, además de en los distintos informes enviados a la Academia, en una serie de artículos, que bajo su firma irán apareciendo periódicamente desde 1886 no solo en publicaciones vascas, como la revista Euskal-Erria, sino también en el $B R A H$. Su labor investigadora a lo largo de la provincia favorecerá su contacto con Hübner, ocupado en estos momentos en la preparación del Suplementum del CIL II. Su colaboración con el epigrafista parece haberse iniciado en torno a 1888 y se mantiene, al menos, hasta 1898 , como se documenta en la correspondencia que ambos mantuvieron (Albertos, 1970). Así, por ejemplo, en 1888 respondiendo a las noticias enviadas por Baraibar sobre una nueva inscripción aparecida en Assa (CIL II, 5814) y a sus indicaciones sobre los números 2923, 2929 y 4919 del CIL II, Hübner le agradece su amabilidad y le solicita, ante la próxima edición de los datos referentes a Álava en el Suplementum, que «como el primer conocedor viviente de estas regiones» le comunique su información sobre aquellos monumentos «tan dignos de ser conocidos y apreciados en España y fuera de ella» ${ }^{54}$. La admiración y el respeto científico que le merecían a Baraibar tanto el investigador alemán como F. Fita le lleva a aceptar, en distintas ocasiones, las correcciones, las lecturas y los comentarios que estos hacen sobre el material que él ha descubierto durante sus exploraciones, en concreto sobre aquél que presentaba mayores dificultades.

En relación con los epígrafes del País Vasco mal conservados, conviene detenerse un momento en la labor de Fita. Como se observa en sus publicaciones y el estudio de los manuscritos y calcos recibidos, el epigrafista español procedía a restituir los textos corrigiendo las transcripciones de los corresponsales a partir de las fotos o los calcos enviados, sin el estudio directo de las piezas (Abascal, 1996). Así sucede con algunas inscripciones de Iruña aparecidas después de la publicación del CIL II (Fita, 1887) y con los epígrafes procedentes de Morga (Vizcaya) y Oyarzun (Guipúzcoa). En algunos casos la conservación ha permitido corregir los textos publicados por Fita que han dado lugar a valoraciones como la realizada por Aranzadi (1914) y aceptada por Michelena (1956: 82-83) sobre la inscripción de Oyarzun (Fita, 1893) (Fig. 7), en la que le acusa de excesiva imaginación.

54. Albertos (1970) reproduce íntegra la carta en su trabajo sobre Baraibar. Lo mismo podría decirse de la tarjeta escrita en marzo de 1898 donde Hübner comenta el envío de una excelente fotografía sobre la lápida de Luzcando al tiempo que le sugiere un suplemento para el renglón 7.

\subsection{El SIGLO XX: EL PAPEL DE LA UNIVERSIDAD Y LOS CENTROS DE INVESTIGACIÓN}

Tras la desaparición de Baraibar las investigaciones conocen un nuevo parón, que se aprecia no solo en Álava sino también en Vizcaya, donde las propuestas de P. de Alzola y C. Echegaray, mencionadas anteriormente, no parecen haber llegado a materializarse ${ }^{55}$. A lo largo del siglo XX la preocupación por la historia primitiva del País Vasco se centra especialmente en la prehistoria, donde los estudios arqueológicos van a conocer un auge, que se mantiene hasta nuestros días. Esta primacía de la antigüedad preclásica, vinculada con el interés por los orígenes de la lengua y el pueblo vasco, es el resultado de la intensificación de una tendencia que se había venido gestando durante el siglo anterior. Como ha resaltado C. Ortiz de Urbina (1996: 160), aunque el progreso de la actividad científica va a ir desmontando poco a poco los viejos esquemas históricos, no se puede negar, por otro lado, la incidencia que todavía ejercían sobre la investigación «aquellas experiencias anteriores tendentes a resaltar el carácter de la raza vasca, primitiva y nunca sometida a invasiones extranjeras». En Álava, donde los restos materiales hasta ahora descubiertos no permitían dudar de la presencia romana, la continuidad en las investigaciones arqueológicas descansa en la labor desarrollada por la Sociedad de Estudios Vascos-Eusko Ikaskuntza y por un grupo formado en el seno de los Hermanos Marianistas de Vitoria, si bien su interés

55. En el Boletín de la Comisión de Monumentos correspondiente al año 1909 queda reflejado el interés de los vocales P. de Alzola y C. Echegaray, ambos correspondientes de la Real Academia de la Historia, por el estudio de los posibles restos romanos (Boletín 1909, cuad. I: 6). En la página 40 y con fecha del 8 de enero de 1908 se recoge a instancia de Echegaray el nombramiento de dos subcomisiones dentro de la Comisión para mejorar su funcionamiento. La primera de ellas, compuesta por los correspondientes de la Academia de la Historia, se encargaría «de estudiar y proponer todo lo que haga relación a objetos de significación histórica y protohistórica, como lápidas, trozos de calzadas, escudos, etc.» En ese mismo año, el 5 de febrero, de nuevo Echegaray presenta «un proyecto de circular para los párrocos y alcaldes de Vizcaya con el fin de conseguir la investigación y recapitulación de la mayor suma de datos referentes a monumentos artísticos, objetos de arte y escudos, lápidas etc.», material que serviría de base para la elaboración de un índice de objetos artísticos e históricos de Vizcaya (Boletín 1909, cuad. I: 41). Esta iniciativa fue presentada a la Real Academia de la Historia recibiendo el beneplácito y la felicitación de F. Fita. No sabemos la repercusión real que estas decisiones tuvieron, pero la ausencia de noticias sobre epigrafía y arqueología romana, así como la valoración de Taracena y Férnandez Avilés sobre el escaso desarrollo de los estudios en estos campos parecen indicar que fue bastante escasa. 
se centra básicamente en la prehistoria ${ }^{56}$. A la sombra de la Sociedad de Estudios Vascos, fundada en 1918, fueron surgiendo diversas agrupaciones culturales como el Laboratorio de Etnología y de Eusko-Folklore y el Centro de Investigaciones Prehistóricas, que comenzaron a funcionar en Vitoria desde el año 1921 (Barandiarán, 1977) ${ }^{57}$. Junto a estudios antropológicos y arqueológicos, merecedores de alabanzas por parte de intelectuales europeos (Barandiarán Irizar, 1983), el Laboratorio organizó dos publicaciones periódicas -el Anuario de la Sociedad de Eusko-Folklore y una hoja mensual denominada Materiales y cuestionarios Eusko-Folklore $(1921)^{58}$ - y formó una colección de materiales arqueológicos, algunos de procedencia romana entre los que se incluían varios restos epigráfi$\cos ^{59}$. Aunque la actividad de la Sociedad no se centraba en la Antigüedad romana, no por ello descuidó la conservación de los restos epigráficos que iban apareciendo en la provincia. De este modo y gracias al interés de

56. La actividad arqueológica de los Hermanos Marianistas estuvo centrada en la prehistoria y en la época romana llegando a formar una colección de materiales entre los que había restos romanos sin que, según parece, hayan existido inscripciones. Sobre el desarrollo de la investigación prehistórica en Álava vid. E. Vallespí, 1966.

57. El Laboratorio de Etnología y Eusko-Folklore, conocido posteriormente como Ikuska, surge del núcleo existente en Vitoria en 1920 (Notas liminares, Eusko-Folklore, Materiales y cuestionarios. Año 34, Octubre-Diciembre 1954, 3. ${ }^{a}$ Serie, n. ${ }^{\circ}$ 1); el Centro de Investigaciones Prehistóricas fue creado en febrero de 1925 (Junta Permanente del 23-II-1925). Hacia el año 1928 surgió el llamado "Grupo Baraibar», cuyo objetivo era principalmente promover el estudio del vascuence y de obras características del País Vasco, organizando conferencias, lecciones, festejos etc. en distintas partes de Álava. Influido por todo este movimiento en favor de la cultura vasca surgió en Laguardia (Álava) la Sociedad de Amigos de Laguardia todavía hoy activa, que formó un Museo local, donde en la actualidad se encuentran depositadas dos aras (HAEp 2545 y 2546) descubiertas en esta localidad (Barandiarán, 1977).

58. La hoja mensual planteaba una serie de cuestionarios sobre diversos aspectos relacionados con la cultura vasca, que servían para las investigaciones posteriores.

59. El Laboratorio surgió como una asociación de carácter católico y al cobijo de la Iglesia, ubicándose su sede y celebrándose sus sesiones en el Seminario de Vitoria. Sin embargo, no tardaron en surgir problemas con las autoridades del Seminario por el carácter de las investigaciones que cuestionaban algunos de los principios de la fe católica y que terminaron obligando a su traslado a un local que la Escuela de Artes y Oficios cedió al Laboratorio. En un primer momento, el cambio afectó solo al material depositado en el Laboratorio siendo el traspaso definitivo de la sede más tarde. Según escribe Barandiarán en su Diario con fecha de 1923: «El Rector del Seminario de Vitoria, declara que tales Anuarios constituyen una mamarrachada. Tampoco quiere que pertenezcan al Museo Diocesano, que en breve se inagurará en el Seminario, los objetos de prehistoria vasca y las lápidas romanas de Álava que yo poseo, pues dice que son tonterías» (Barandiarán Irizar, 1983: 88 y ss.).
J. M. de Barandiarán fueron depositadas en el Museo local que se había instalado en la Escuela de Artes y Oficios en Vitoria, junto a otras inscripciones cuya identificación es dudosa, las de Foronda y Santa Cruz de Campezo descubiertas de forma fortuita en los años 1919 y entre 1930-32, respectivamente. Ninguna de las dos llegó a ser editada correctamente, sin embargo, el investigador guipuzcoano dedicó a la primera una breve nota en la Hoja mensual de Eusko-Folklore correspondiente al mes de diciembre de 1925, en la que daba cuenta del texto y de las circunstancias de su hallazgo ${ }^{60}$.

Durante todo este período anterior a la Guerra Civil la única publicación que incluye testimonios epigráficos es el artículo realizado por J. M. Corta en 1928. Tomando como eje las vías de comunicación que atravesaban la provincia, el autor hace una recopilación de los restos arqueológicos relacionados con ellas, entre los que se encuentran todas las inscripciones editadas hasta ese momento. Tras el freno provocado por el levantamiento de 1936 y el estallido del conflicto, las investigaciones vuelven a reanudarse en los años cuarenta. Es precisamente en esta década cuando comienzan a sentirse en España los efectos de la reforma universitaria de $1928^{61}$, que había convertido la epigrafía y la numismática en disciplinas oficiales dentro de la Licenciatura de Historia. A partir de ahora la Universidad comienza a jugar un papel cada vez más creciente, sin que esto suponga la desaparición de los eruditos locales o de los conservadores de museos. Así en el País Vasco donde la vinculación de la Epigrafía y Numismática con la Universidad del País Vasco constituye un fenómeno tardío ${ }^{62}$, los estudios en estos

60. J. M. de Barandiarán da cuenta de la lápida de Foronda ( $H A E p$ 2537) transcribiendo el texto sin ningún criterio epigráfico en una nota publicada en la página 45 de la Hoja mensual de Eusko-Folklore correspondiente a Diciembre de 1925, n. ${ }^{\circ}$ LX. La primera noticia que tenemos de la inscripción de Santa Cruz de Campezo (HAEp 1776) aparece en la Guía Sumaria de D. Fernández Medrano publicada en 1948, donde se indica su depósito en la Sociedad. En Museo provincial de Álava. Arqueología (Vitoria, 1968: 16, n. ${ }^{\circ}$ 3) se describe con más precisión las condiciones de su hallazgo. El texto no deja de ser ilustrativo del interés que despertaba la epigrafía romana en aquel momento: «Se encontraba en el interior de la ermita de Nuestra Sr. ${ }^{a}$ de Ibernalo. Al efectuar en 1930-32 unas obras de reparación, se retiró al exterior recostándola sobre una encina, hasta que en 1934 Barandiarán la recogió, enviándola al Museo de Eusko-Ikaskuntza (en una sala de la Escuela de Artes y Oficios de Vitoria). En 1941, aún sin desembalar, fue trasladada al Museo Provincial entonces en formación»".

61. Con la Reforma Universitaria de 1928, que instituye mediante un decreto ley de 19 de mayo la enseñanza oficial de la Epigrafía y Numismática, el papel de la universidad se dejará sentir cada vez más, si bien no se hace perceptible hasta los primeros años de la posguerra (1940-1945). Enciclopedia Jurídica Española, t. II, 943-944.

62. La creación dentro de la Universidad del País Vasco de la Facultad de Filosofía y Letras, donde se imparte la licenciatura en Geografía e Historia no tiene lugar hasta el año 1978. 
campos durante mucho tiempo van a continuar siendo impulsados por organismos y centros creados bajo el patrocinio de instituciones provinciales y locales desde los que se solicita la colaboración de personas pertenecientes a universidades foráneas ${ }^{63}$. De esta relación derivan los trabajos, por ejemplo, de G. Nieto ${ }^{64}$, así como de aquellos investigadores que, siendo originarios del País Vasco, estaban ejerciendo su profesión fuera de él, como L. Michelena, I. Barandiarán o M. ${ }^{\mathrm{a}}$ L. Albertos.

El número de hallazgos epigráficos aumenta entre los primeros años de la postguerra y el último decenio del siglo XX, especialmente en Álava como consecuencia fundamentalmente de las excavaciones que se realizan en los yacimientos de Iruña y Arcaya y en el derrumbe de las ermitas de Alaiza-Luzcando y Ocariz. Al mismo tiempo la evolución conocida por la ciencia epigráfica desde la segunda mitad del siglo XIX se va a dejar sentir también en el estudio de las inscripciones del País Vasco. Tras el hito que supone la edición del CIL se produce la aparición de corpora que tratan de recopilar de forma sistemática los materiales pertenecientes a una provincia o a una ciudad antigua. En un principio se puede decir que estos compendios, cuya realización se beneficia de los avances técnicos -particularmente de los fotográficos-, reproducen en su filosofía los planteamientos que habían presidido el $C I L$, concediendo una total primacía al texto. $\mathrm{Su}$ finalidad parece ser la de completar el registro elaborado en el Corpus y sus suplementos (Suplementum y $E E$ ) dando a conocer la mayor cantidad posible de inscripciones, en ocasiones, sin efectuar un trabajo de inspección sobre el terreno y tomando la autoridad de Hübner como una garantía suficiente para la aceptación de la lectura de un documento. La publicación en 1951 en el $B R A H$ del trabajo de M. Gómez Moreno

63. Entre estos centros de investigación no universitarios cabe citar el Instituto Alavés de Arqueología y la Sociedad de Ciencias Aranzadi. Arkeologiarako Arabar InstitutuaInstituto Alavés de Arqueología, 1995; Goicoetxea, 1997.

64. Bajo el patrocinio del Consejo de Cultura de la Diputación Foral de Álava y con la colaboración de la Universidad de Valladolid a través del Seminario de Arte y Arqueología se desarrollarán entre 1949 y 1954 una serie de excavaciones en Iruña bajo la dirección de G. Nieto, secretario del Seminario y director del Museo Arqueológico de Valladolid, y en las que colaboran también el Sr. Ossaba, Director del Museo de Burgos, R. Apraiz, Dtor. del Museo Numantino, y D. Fernández Medrano, Comisario de Excavaciones de Álava. Estos trabajos ponen al descubierto nuevos restos epigráficos de los que escasamente tenemos noticias en los informes publicados en el Boletín del Seminario (Nieto, 1948-1949a; 1948-1949b; 1949-1950; 1951-1952) y en la memoria publicada en 1958 bajo el título de El Oppidum de Iruña. A todas estas referencias se pueden añadir las actas de las reuniones de Consejo de Cultura de la Diputación conservadas en el A.T.H.A., en las que se trataba el tema de las prospecciones y excavaciones en Iruña con la participación de G. Nieto y la Universidad de Valladolid. sobre la epigrafía vizcaína participa de algunos de estos criterios. Como él mismo indica, su estudio, en el que incluye inscripciones no romanas, ha sido hecho sin la autopsia directa del material utilizando los datos que le ha proporcionado un erudito, J. A. Basanta ${ }^{65}$, completados con la información obtenida de publicaciones anteriores. Su principal preocupación radica en la datación de los monumentos y en la transcripción de los textos, donde junto a la edición de estelas hasta entonces inéditas como las de Lemona o la de Zaldu, revisa y corrige la lectura efectuada por Fita de los epígrafes de Morga y Forua (Gómez Moreno, 1951). Después del artículo de Gómez Moreno, Ugartechea (1962) lleva a cabo una recopilación de toda la epigrafía provincial vizcaína.

Para el caso de Álava el corpus de inscripciones no es publicado hasta 1967 cuando J. C. Elorza en su artículo «Ensayo topográfico de epigrafía romana alavesa» (1967), reúne todo el material conocido hasta ese momento (118 epígrafes), incluyendo el descubierto recientemente y aquél que permanecía inédito entre los papeles manuscritos de Baraibar. Su planteamiento es idéntico al del CIL: indicación del material, medidas, procedencia, paradero actual, texto, bibliografía básica $\mathrm{y}$, en algunos casos, un breve comentario. Al final del mismo abre un apartado de conclusiones en el que efectúa una breve valoración de la onomástica y la decoración dejando fuera los aspectos cronológicos. Ahora bien, cuando Elorza publica este estudio ya había aparecido en los inicios de la década anterior dos obras, que incidían en dos aspectos diferentes sobre los que era necesario detenerse para perfeccionar el método de análisis. En 1952 J. Mallon publica su Paléographie romaine y en $1953 \mathrm{~J}$. M. Navascués lee su discurso de ingreso en la Academia bajo el título de El concepto de epigrafía. Consideraciones sobre la necesidad de su ampliación. El primero contribuye desde sus aportaciones en el campo de la paleografía a una comprensión renovada del proceso de fabricación de una inscripción partiendo de un texto escrito en cursiva (Etienne y Le Roux, 1990: 116). El segundo reclama la necesidad de prestar atención al soporte, efectuando un estudio detallado de la decoración, el material y la tipología (Ramírez Sánchez, 2005) ${ }^{66}$. La minuciosidad con la que debe ser observada la escritura y el monumento provoca a partir de ahora la necesidad de considerar la inscripción en su totalidad. Este interés por el propio epígrafe y por la información que se desprende de su análisis formal -cronología, officina o taller donde ha sido fabricado, etc.- va a tener también su reflejo en la

65. «Aún valga declarar que, así esto como los materiales ahora presentados, se deben íntegros al susodicho erúdito y querido amigo, pues directamente nada se ha puesto a mi alcance, ni mi presencia en Bilbao, ha muchos años pasó de visitas casi accidentales y sin plan de estudio», Gómez Moreno, 1951: 197.

66. Vid. también el trabajo posterior de Navascués (1963) sobre las inscripciones de Salamanca. 
epigrafía del País Vasco. Desde esta nueva perspectiva se realizan una serie de estudios sobre la decoración, que en ocasiones tienen un carácter comarcal o regional y en otras abarcan ámbitos culturales o geográficos más amplios. Entre estos se incluyen los trabajos realizados por Elorza (1969; 1970; 1976), Marcos Pous y García Serrano (1972) o Marco Simón (1978), este último desde un punto de vista iconográfico.

A partir de los años ochenta aumentan de forma considerable las publicaciones, en unos casos, como consecuencia de la revisión de ediciones o de lecturas e interpretaciones (Rodríguez Colmenero y Carreño, 1981; Azcárate, 1987), en otros, del hallazgo de nuevas inscripciones como en las ermitas de Ocáriz y AlaizaLuzcando (García y Sáenz de Buruaga y San Vicente, 1985a; 1985b) y en la iglesia de San Román de San Millán en Álava (Sáenz de Buruaga y Sáenz de Urturi, 1994), donde ya se conocían algunos ejemplares, y, por último, en trabajos de excavación (Sáenz de Buruaga, 1988; Loza y Ortiz de Urbina, 1992; Nuñez, Martínez, Ciprés y Gorrochategui, 2012; Ciprés, Nuñez y Gorrochategui, 2015). Todo ello ha hecho que el número de epígrafes romanos se haya incrementado, siendo de nuevo la provincia de Álava la que ha registrado la mayor parte de los nuevos testimonios ${ }^{67}$. En el extremo opuesto se sitúa Guipúzcoa, donde tan solo se han documentado dos nuevas inscripciones procedentes de Cegama (Echevarría y Urteaga, 1988) y Mondragón (Abascal, 2010).

Paralelamente al interés que despiertan las inscripciones por sí mismas o como testigos de la presencia romana, a lo largo del siglo XX se refuerza su importancia como una fuente básica para el conocimiento de la Antigüedad en el País Vasco. Uno de los aspectos estudiado en su consideración como una fuente histórica es el intento de datación de los epígrafes llevado a cabo por Echevarría en 1989. Sin embargo el reducido número de hallazgos, sobre todo en Vizcaya y Guipúzcoa, así como el carácter funerario de la mayor parte de los epígrafes y la ausencia casi absoluta de documentos honoríficos o monumentales ha condicionado en cierto modo la orientación de los estudios, de forma que los investigadores han primado el análisis de la onomástica y de la teonimia (Albertos, 1970b y 1985; González, 1984; Gorrochategui, 1995; Ciprés, 2006) ${ }^{68}$,

67. Sin pretender ser exhaustivos, a estas habría que añadir otras publicaciones como, por ejemplo, las de Ruiz de Loizaga (1981) y Sáenz de Buruaga (1990).

68. En ocasiones se ha valorado la información lingüística partiendo de la aceptación de las lecturas dadas por el CIL o Fita, sin tener en cuenta los problemas que planteaba la conservación del monumento o la reconstrucción del texto, admitiendo, por ejemplo, como indígenas aquellos nombres, cuya lectura en ocasiones no es posible confirmar. Generalmente estos nombres para los que no existe ningún paralelo han sido aceptados como un hapax. Estamos haciendo alusión, por supuesto, a aquellas inscripciones en mal estado de conservación cuya transcripción es problemática. con el objetivo de evaluar el proceso de integración de las gentes de este territorio en el mundo romano. Aunque el desarrollo de la epigrafía y de la arqueología como disciplinas científicas ha hecho que deje de cuestionarse la validez histórica de los restos romanos, en su interpretación histórica durante un tiempo todavía seguirán perviviendo las ideas vinculadas con el control militar o la resistencia indígena, en este último caso también bajo la influencia de los procesos de descolonización en el estudio de las sociedades conquistadas por Roma.

\section{REFERENCIAS}

Abascal, J. M. (1996). Fidel Fita y la epigrafía hispanoromana. Boletín de la Real Academia de la Historia, CXCIII, cuaderno II, 305-334.

Abascal, J. M. (1999). Fidel Fita (1835-1918). Su legado documental en la Real Academia de la Historia. Madrid: Real Academia de la Historia.

Abascal, J. M. (2010). CIL II 4977 (Mondragón, Guipúzcoa). Una inscripción romana enterrada por la Inquisición y conservada en Segobriga. Archivo Español de Arqueología, 83, 127-131.

Albertos, M. ${ }^{a}$ L. (1970a). Federico Baraibar y la Epigrafía romana de Álava. Homenaje del Instituto Femenino de Enseñanza Media de Vitoria a Federico Baraibar. Vitoria: Diputación Foral de Álava.

Albertos, M. ${ }^{a}$ L. (1970b). Álava prerromana y romana. Estudio lingüístico. Estudios de Arqueología Alavesa, 4, 107-234.

Albertos, M. ${ }^{a}$ L. (1985). La onomástica personal en las inscripciones de Ocáriz. Estudios de Arqueología Alavesa, 12, 365-377.

Alzola, P. de (1906). Lápida romana de Forua. Euskal-erria, $L V, 512-516$.

Alzola, P. de (1908). Lápida romana de Forua. Un escrito de Alzola dirigido a la Comisión de Monumentos de Vizcaya. Euskal-erria, LVIII, 140-142.

Amador de los Ríos, J. (1871). Estudios monumentales y arqueológicos sobre las Provincias Vascongadas. Revista de España, 20, 497-507; 21, 5-29.

Anónimo (1792). Guía de Forasteros en Vitoria por lo respectivo a las tres Bellas Artes. Vitoria: Imprenta B. Manteli.

Aranzadi, T. de (1914). Sobre la lápida de Andre-arriaga. Euskalerriaren Alde, IV, 44-45.

Areta Armentia, L. M. ${ }^{\text {a }}$ (1976). Obra literaria de la Real Sociedad Vascongada de Amigos del País. Vitoria: Caja de Ahorros Municipal.

Arkeologiarako arabar institutua-Instituto alavés de arqueología (1995). La reconstrucción del pasado alavés a través de la Arqueología. Revista Internacional de Estudios Vascos, XL(2), 413-426. 
Ayala, F. J. de (1846). Antigüedades romanas en la provincia de Álava. El Lirio, I, 129-130, 138-139, 146-147, 153-154, $161-162,169-170$ y $177-179$.

Azkarate, A. (1987). Epigrafía vizcaína. Sobre el supuesto cristianismo de algunos de sus ejemplares de época romana. Kobie, 16, 77-95.

Baraibar, F. (1883). Antigüedades de Iruña. Discurso leído en el Ateneo de Vitoria al abrirse el curso de 1882 a 1883. Ateneo, IX, 1-9, 17-24, 44-48, 57-61.

Baraibar, F. (1886). Antigüedades de Iruña. Euskal-erria, $X I V, 149-153$.

Baraibar, F. (1895a). Lápidas romanas inéditas de Marañón, Pancorbo, San Martín de Galvarín y Luzcando en las provincias de Navarra, Burgos y Álava. Boletín de la Real Academia de la Historia, XXVI, 46-54.

Baraibar, F. (1895b). Lápidas romanas inéditas en Navarra y Álava. Euskal-erria, XXXII, 218-222;

Baraibar, F. (1907). Lápidas romanas de Tricio. Boletín de la Real Academia de la Historia, L, 256-270.

Baraibar, F. (1912). Museo incipiente. Suplemento a la memoria del curso 1911 á 1912 en el Instituto General y Técnico de Vitoria. Madrid: Establecimiento Tipográfico de Fortanet.

Baraibar, F. (1914). Lápidas de La Puebla de Arganzón y Laguardia. Boletín de la Real Academia de la Historia, LXIV, 176-181.

Barandiarán, J. M. (1977). Los estudios vascos antes de la Guerra del 36 (su esbozo visto desde Álava). Euskera, 22, 88-94.

Barandiarán Irizar, L. (1983). José Miguel de Barandiarán. Patriarca de la cultura vasca. Obras completas. Bilbao: Ed. La Gran Enciclopedia Vasca.

Castro, C. de (1915). Catálogo monumental de España. Inventario general de los monumentos históricos y artísticos de la Nación. Provincia de Álava. Madrid: Ministerio de Instrucción Pública y Bellas Artes, Est. Tipográfico Sucesores de Rivadeneyra.

Ciprés, P. (2006). La onomástica de las inscripciones romanas del País Vasco. Estructura del nombre personal y estatuto jurídico. Veleia, 23, 85-128.

Ciprés, P. (2007-2008). Sobre la inscripción HAEp 2540 procedente de Iruña, Álava. Veleia, 25, 1059-1068.

Ciprés, P, Nuñez, J. y Gorrochategui, J. (2015). Nuevo fragmento de inscripción procedente de Veleia (Iruña de Oca, Álava) con posible expresión de un magistrado local. Veleia, $32,217-229$.

Corta, J. M. (1928). Vías romanas en Álava. Euskalerriaren Alde, XVIII, 326-361.

Duplá, A. y Cortadella, J. (2014). Nota sobre Antigüedad, nacionalismo(s) e historiografía: dos estudios de caso en las historiografías vasca y catalana. Veleia, 31, 261-276.

Duplá, A. y Emborujo, A. (1991). El vasco cantabrismo: mito y realidad en la historiografía sobre el País Vasco en la
Antigüedad. En J. Arce y R. Olmos (Coords.)., Historiografia de la arqueología y de la historia antigua en España (siglos XVIII-XX) (pp. 107-112). Madrid: Ministerio de Cultura.

Echegaray, C. de (1921). Provincia de Vizcaya. En F. Carreras Candi (Dir.). Geografia general del País Vasco-Navarro. Barcelona: Alberto Martín.

Echevarría, A. y Urteaga, M. (1988). La inscripción funeraria de época romana de la ermita de San Pedro (Zegama, Guipúzcoa). Munibe, 40, 165-169.

Echevarría, A. (1989). La cronología de las inscripciones funerarias latinas de Álava. Munibe, 41, 133-152.

Elorza, J. C. (1967). Ensayo topográfico de epigrafía romana alavesa. Estudios de Arqueología Alavesa, 2, 119-186.

Elorza, J. C. (1969). Un taller de escultura romana en la divisoria de Álava y Navarra. Cuadernos de trabajo de la Escuela Española de Roma, XIII, 54-86.

Elorza, J. C. (1970). Estelas romanas en la provincia de Álava. Estudios de Arqueología Alavesa, 4, 235-250.

Elorza, J. C. (1976). Estelas romanas decoradas en el territorio de autrigones, berones, caristios, várdulos y vascones. (Tesis doctoral inédita). Universidad Autónoma de Madrid. Madrid.

Etienne, R. y Le Roux, P. (1990). Un siècle de recherches sur l'épigraphie romaine de la péninsule Ibérique. En Actes $d u$ colloque international pour le centenaire de L'Année épigraphique (pp. 101-134). Paris: PUF.

Fernández Sebastián, J. (1991). La génesis del fuerismo. Prensa e ideas políticas en la crisis del Antiguo Régimen (País Vasco, 1750-1840). Madrid: Siglo XXI de España Editores, S.A.

Fita, F. (1887). Epigrafía romana. Boletín de la Real Academia de la Historia, X, 399-408.

Fita, F. (1893). Inscripciones romanas inéditas de Añavieja y Oyarzun. Boletín de la Real Academia de la Historia, XXIII, 484-490.

Fita, F. (1899). Antigüedades e Historia del País Vasco. Boletín de la Real Academia de la Historia, XXXIV, 164-172.

Flórez, E. (1877). La Cantabria. Disertación sobre el sitio y extensión que tuvo en tiempo de los romanos la región de los cántabros, con noticia de las regiones confinantes y de varias poblaciones antiguas. Discurso preliminar al tomo XIV de la España Sagrada, en que se trata de la Provincia Tarraconense. Madrid: Antonio Marín.

García, E., Sáenz De Buruaga, J. A. y San Vicente, I. (1985a). Estelas y lápidas romanas inéditas del este de Álava. Estudios de Arqueología Alavesa, 12, 343-363.

García, E., Sáenz De Buruaga, J. A. y San Vicente, I. (1985b). Estelas, lápidas y fragmentos epigráficos inéditos de la ermita de San Miguel de Ocariz (Álava). Estudios de Arqueología Alavesa, 12, 285-342.

Gimeno, H. (2012). Los estudios epigráficos en España en el siglo XVIII. En M. Almagro Gorbea y J. Maier Allende (Coords.). De Pompeya al Nuevo Mundo: la corona española 
y la arqueología en el s. XVIII (pp. 143-156). Madrid: Real Academia de la Historia.

Goicoetxea Marcaida, A. (1997). La Sociedad de Ciencias Aranzadi 1947-1997. Revista Internacional de Estudios Vascos, 42, 2, 425-435.

Gómez Moreno, M. (1951). De epigrafía Vizcaína. Boletín de la Real Academia de la Historia, CXXVIII, 197-217.

González Rodríguez, M. ${ }^{a}$ C. (1984). Síntesis histórica de epigrafía romano-alavesa. Veleia, 1, 217-231.

Gorrochategui, J. (1995). Los Pirineos entre Galia e Hispania: las lenguas. Veleia, 12, 181-234.

Henao, G. (1689), Averiguaciones de las antigüedades de Cantabria. Salamanca: Eugenio Antonio García (Reeditado en 1894. Tolosa: Librería y encuadernación E. López.

Iturriza, J. R. (1885). Historia General de Vizcaya. Bilbao: Imp. De Cipriano Lucena y Compañía.

Izaguirre, R. (1971). Cómo se deforma una figura. Juan Guillermo Thalacker y las minas de Oyarzun. Munibe, 23, 497-505.

Labayru y Goicoechea, E. J. de (1895). Historia General del Señorio de Bizcaya. Bilbao: Casa Editorial La Propaganda; Madrid: Librería de Victoriano Suarez.

Larrañaga Elorza, K. (1996). El historiador A. d'Oihenart (1592-1667) y su tratamiento del tema de los orígenes vascos. Vasconia. Cuadernos de Historia-Geografia, 24, 115-143.

Larrañaga Elorza, K. (1998-1999). Vascocantabrismo y arqueología. Memorias de Historia Antigua, XIX-XX, 111-198.

Le Roux, P. (1984). E. Hübner ou le métier d'épigraphiste. En Épigraphie Hispanique. Problèmes de méthode et d'édition (pp. 17-31). Paris: Diffusion E. de Boccard.

Loza Lengarán, R. y Ortiz de Urbina, C. (1991). Un caso de lápida romana decorada con arquerías ultra-semicirculares en Arcaya (Álava). Eusko Ikaskuntza. Cuadernos de Sección. Prehistoria y arqueología, 4, 265-276.

Madinaveitia, M. (1845). Antigüedades. El Lirio, I, 9-10.

Mallon, J (1952). Paléographie romaine. Madrid: CSICInstituto Antonio de Nebrija de Filología.

Mañaricúa, A. E. de (1973). Historiografía de Vizcaya (desde Lope García de Salazar a Labayru). Bilbao: La Gran Enciclopedia Vasca.

Marco Simón, F. (1978). Las estelas decoradas de los conventos caesaraugustano y cluniense. Caesaragusta, 43-44, 3-259.

Marcos Pous, A. y García Serrano, A. (1972). Un grupo unitario de estelas funerarias de época romana con centro en Aguilar de Codés. Estudios de Deusto, 20, 318-328.

Martínez Salazar, A. (2003). Diego Lorenzo del Prestamero: un erudito e ilustrado alavés. En Lorenzo Prestamero (17331817). Una figura de la Ilustración alavesa (pp. 15-42).
Vitoria-Gasteiz: Diputación Foral de Álava. Departamento de Cultura.

Michelena, L. (1956). Guipúzcoa en la época romana. Boletín de la Real Sociedad Vascongada de Amigos del País, XII(1), 69-94.

Miñano, S. de (1826-1828). Diccionario Geográfico Estadístico de España y Portugal. Madrid: Imprenta Pierart-Peralta.

Moret, J. de (1655). De obsidione Fontirabiae libri tres. Lyon: (traducción castellana de M. Silvestres de Arlegui (1763). Empeños del valor, y bizarros desempeños, o sitio de Fuenterrabia. Pamplona: J. M. de Ezquerro impresor de los Reales Tribunales de Navarra).

Moret, J. de (1766). Investigaciones históricas de las antigüedades del Reyno de Navarra. Pamplona: Imprenta de Pascual Ibáñez.

Navascués, J. M. (1953). El concepto de epigrafía. Consideraciones sobre la necesidad de su ampliación. Discurso de ingreso en la Real Academia de la Historia. Madrid.

Navascués, J. M. de (1963). Caracteres externos de las antiguas inscripciones salmantinas. Los epitafios de la zona occidental. Boletín de la Real Academia de la Historia, CLII, 159-223.

Nieto, G. (1948-1949a). Excursiones realizadas por el Seminario durante el curso actual. Boletín del Seminario de Estudios de Arte y Arqueología, XV, 9-14.

Nieto, G. (1948-1949b). El yacimiento de Iruña (Álava). Informe sobre las prospecciones realizadas en 1949, Boletín del Seminario de Estudios de Arte y Arqueología, XV, 91-102.

Nieto, G. (1949-1950). Labor realizada por el Seminario durante el curso actual. Boletín del Seminario de Estudios de Arte y Arqueología, XVI, 5-6.

Nieto, G. (1951-1952). La estela de Iruña (Álava). Boletín del Seminario de Estudios de Arte y Arqueología, XVIII, 13-15.

Nieto, G. (1958). El Oppidum de Iruña. Vitoria: Diputación Foral de Álava.

Nuñez, J., Martínez, D., Ciprés, P. y Gorrochategui, P. (2012). Nueva ara dedicada a Mater Dea procedente de Veleia (Iruña de Oca, Álava). Veleia, 29, 441-452.

Ortiz de Urbina, C. (1996). El desarrollo de la arqueología en Alava: condicionantes y conquistas (siglos XVIII y XIX). Vitoria: Diputación Foral de Álava.

Ortiz de Urbina, C. (1997). La Real Sociedad Bascongada y la arqueología en el País Vasco del s. XVIII. En G. Mora y M. Díaz-Andreu (Eds.). La cristalización del pasado: génesis $y$ desarrollo del marco institucional de la arqueología en España (pp. 77-90). Málaga: Universidad de Málaga-CSIC.

Ortiz de Zárate, R. (1866). Jamás los romanos conquistaron completamente a los vascongados y nunca estos belicosos pueblos formaron parte integrante del Imperio de los Césares (3. ${ }^{a}$ edición). Vitoria: Imprenta de Ciriano Guinea. 
Prestamero, L. del. Carpeta de manuscritos. Archivo Histórico-Documental de la Diputación Foral de Álava, DH-1080-30; DH-1299-2.7.

Prestamero, L. del (1900). Camino militar romano que pasaba por Álava. En V. González de Echávarri. Alaveses ilustres (pp. 275-316). Vitoria: Imprenta Provincial.

Ramírez Sánchez, M. (2005). El concepto de epigrafía. Consideraciones sobre la necesidad de su ampliación cincuenta años después. Signo. Revista de Historia de la Cultura Escrita, 15, 47-76.

Real Academia de La Historia (1802). Diccionario Geográfico-Histórico. 2 vols. Madrid: Imprenta de la Viuda de Joaquín Ibarra.

Reboredo Olivenza, J. D. (1988). El Ateneo Científico, Literario y Artístico de Vitoria 1866-1900. Vitoria: Diputación Foral de Álava.

Rivera, A. (1992). La ciudad Levítica. Continuidad y cambio en una ciudad del interior (Vitoria, 1876-1936). Vitoria: Diputación Foral de Álava.

Rodríguez Colmenero, A. y Carreño, M. ${ }^{a}$ C. (1981). Epigrafía vizcaína: revisión, nuevas aportaciones e interpretación histórica. Kobie, 11, 81-163.

Ruiz de Loizaga, S. (1981). Un ara votiva en Comunión. Estudios de Arqueología Alavesa, 10, 297-306.

Sáenz de Buruaga, A. (2003). Diego Lorenzo del Prestamero: y las antigüedades romanas alavesas. En Lorenzo Prestamero (1733-1817). Una figura de la Ilustración alavesa (pp. 45-71). Vitoria-Gasteiz: Diputación Foral de Álava. Departamento de Cultura.

Sáenz de Buruaga, J. A. (1988). Nuevas inscripciones de época romana en Álava. Estudios de Arqueología Alavesa, 16, 531-556.
Sáenz de Buruaga, J. A. (1990). A propósito de algunos epígrafes romanos de Iruña y Asteguieta a través de un manuscrito de L. Prestamero. Estudios de Arqueología Alavesa, 17, 129-134.

Sáenz de Buruaga, J. A. y Sáenz de Urturi, P. (1994). La epigrafía romana de San Román de San Millán (Álava). Veleia, $11,49-82$

Santoyo, J. C. (1972). Viajeros por Álava (S. XV a XVIII). Vitoria: Caja de Ahorros de la Ciudad de Vitoria.

Stylow, A. U. (1984). CIL II Supplementum. Proyecto y estado actual. En Epigraphie Hispanique. Problèmes de méthode et d'édition (pp. 365-371). Paris: Diffusion E. de Boccard.

Stylow, A. U. (1995). Von Emil Hübner zur Neuauflage von CIL II. Madrider Mitteilungen, 36, 17-29.

Stylow, A. U. y Gimeno, H. (2004). Emil Hübner. En Pioneros de la Arqueología en España del siglo XVI a 1912. Zona Arqueológica, 3, 333-340.

Taracena, B. y Fernández Avilés, A. (1945). Memoria sobre las excavaciones en el castro de Navárniz (Vizcaya). Madrid: Junta de Cultura de la Excelentísima Diputación de Vizcaya.

Thalacker, J. G. (1883). El monte Aya y sus minas. Euskalerria, VIII, 446-449, 474-477 y 501-506.

Ugartechea, J. M. (1962). Notas sobre estelas, lápidas e inscripciones funerarias vizcaínas. Anuario de Eusko Folklore, $X I X, 131-171$.

Urdiain, C. (1985). Fuentes documentales para la Historia de la Real Sociedad Bascongada de Amigos del País. Sus archiveros: Pedro M. de Unceta y Diego Lorenzo de Prestamero. Ernaroa, 1, 37-92.

Variedades euskaras (1883). Euskal-erria, VIII, 155. 